\title{
An Adaptive Water Resources Management Framework With Combined Policies to Confront Adverse Effects and Risks Due to Population- industry Transformation Into a Floodplain Area
}

Xueting Zeng ( $\square$ zxting1231@163.com )

Capital University of Economics and Business

Junlong Zhang

Qingdao University

Jia Liu

Capital University of Economics and Business

\section{Research Article}

Keywords: location-entropy based PVRA model, coupla-risk analysis, stochastic-fuzzy method, population-industry transformation, scenario analysis, floodplain

Posted Date: November 5th, 2021

DOl: https://doi.org/10.21203/rs.3.rs-890947/v1

License: (c) (1) This work is licensed under a Creative Commons Attribution 4.0 International License.

Read Full License 
1 An adaptive water resources management framework with combined policies to confront

$4 \quad$ Xueting Zeng ${ }^{*}$, Junlong Zhang ${ }^{2}$, Jia Liu ${ }^{3}$

5

\section{adverse effects and risks due to population-industry transformation into a floodplain area}

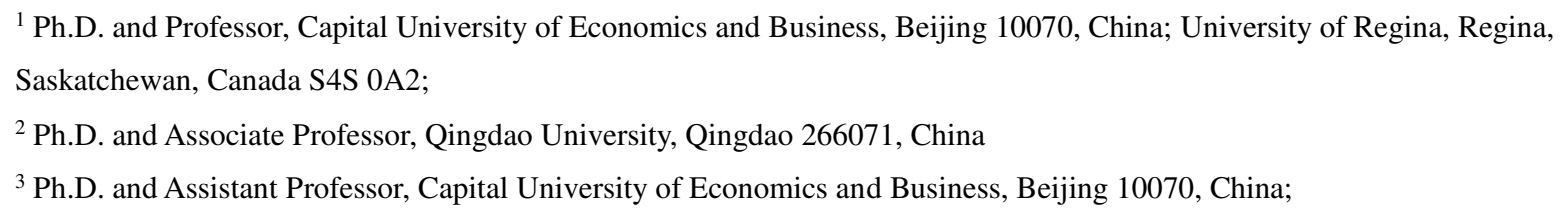

Abstract In this study, an adaptive water resource management framework with combined policies (AWFP) is developed for mitigating adverse effects on water resource in a floodplain area due to population-industry transformation in context of coordinative development of urban agglomeration. A location-entropy based PVRA model (LE-PCRA) and coupla-risk analysis (CRA) can be introduced to reflect the adverse effects of industrial information and driven population on water resources; meanwhile risks (including water shortage, soil loss and flood control) and corresponding correlations have been shown in the risk maps. Moreover, an adaptive scenario analysis based stochastic-fuzzy method (ASSF) can be embedded into an AWFP to deal with multiple uncertainties and their interactions due to subjective and artificial factors. The proposed AWFP is applied to a practical case study of Yongding river floodplain region for confronting adverse effects on water resources due to population-industry transformation in the context of coordinative development of Beijing-Tianjin-Hebei urban agglomeration, China. The results were obtained to reflect the negative effects of population-industry transformation and corresponding water allocation patterns in floodplain, which is effective to confront natural and artificial damages (such as water deficit, water and soil loss, and flood damage), risks and function degradation of floodplain contemporarily. Meanwhile, 
1 various policy scenarios (such as farmland returning to wetland, improvement of water resource

2 utilization efficiency, water diversion and flood control) can be analyzed to support adjusting

3 current population-economy strategies and water management patterns to accommodate source

4 function of floodplain with a risk-averse and sustainable manner.

5

6 Keywords: location-entropy based PVRA model; coupla-risk analysis; stochastic-fuzzy method;

7 population-industry transformation; scenario analysis; floodplain; 


\section{Introduction}

4 In the process of urban agglomeration development, the new function design of each cities based on a comprehensive function for a cross-reginal collaborated goal can accelerate industrial

6 relayout and population movement. Central cities can distribute labor intensive industries to

7 backward areas for optimizing their industrial structure and release resource-environment

8 stresses, but which would bring about new ecological challenges for some backward areas.

9 Particular in some special function location areas (e.g., water source region, store floodwater

10 district, and ecological function zone) of backward areas, excessive human activities due to

11 mitigation of population and industry from core area can damage the source function to reduce

12 resource-environment carrying capacity, leading various negative effects. For instance, Yongding

13 river floodplain in Hebei province has been undertaken the responsibility of protecting the flood

14 control safety of Beijing, Tianjin and Hebei areas. However, in the context of coordinative

15 development of Beijing-Tianjin-Hebei urban agglomeration, intensive development and

16 construction due to population-industry transformation (into floodplain) can increases the risk of

17 disaster potential loss and flood control investment. Meanwhile, the urbanization process can

18 seriously damag the capacity of soil storage, and changes the surface circulation characteristics

19 of precipitation. In addition, the excessive exploitation and utilization of water resources will

20 easily lead toincreased water shortages, lower groundwater levels, serious soil erosions and other

21 ecological problems in floodplain areas (Rong et al., 2019). Therefore, how to identify the

22 adverse influence on floodplain in response to excessive human activities (due to

23 population-industry transformation) becomes an important issue for constructing an adaptive 
water resources management framework urban agglomeration development.

3 Previously, various research works have addressed the negative effects from excessive human

4 activities in a floodplain area. For instance, Olsen et al., (2000) analyzed the impacts of human

5 activities (including land-use changes, channel modifications, and economic development) on

6 flood storage and detention areas, where all above nonstationary conditions, variability and risk

7 can be handled by a dynamic floodplain management model. Knox (2006) used historical data

8 over long periods to reflect the effects of agricultural land use exploitation on floodplain

9 sedimentation, hydrologic alteration and geomorphic changes, which would increase flood risk.

10 Horta et al., (2016) developed an enhanced stochastic frontier panel model and location-entropy

11 method to reflect the negative correlation between population development and natural resources

12 supply in the processes of urbanization. Zeng et al., (2021) explored a GIS and PSR evolution

13 method to identify various risk (water shortage, flooding, soil erosion and pollution) caused by

14 population growth and economic development in a floodplain. In general, previous research

15 works have focused on simulation method, GIS, risk assessment system and statistic analysis

16 model to reflect the effect of human activities on water stress in a floodplain, which indicated

17 that population-economy development would bring about great challengea for human-water

18 relationship. Therefore, numbers of effective manners (e.g., optimization method, adaptive

19 management mode and policy analysis) have been proposed to balance the relationship between

20 human activities and water resource management. For example, Simmons (2007) developed the

21 concept of living with water as a complex entity to reflect the interaction between two natural

22 cycles (including human economy the earth's hydrological system) with three levels (individual,

23 social, and ecological), which would attest technical means (capture, storage, and irrigation) 
1 reducing water deficit, but leading greater uncertainty. Sanon et al., (2012) proposed a multi

2 criteria decision method to address trade-offs between the stakeholder's objectives related to

3 management options for the restoration of an urban floodplain in the context of urban expansion,

4 which can support for generating useful management cost and flood risk control. Zeng et al.,

5 (2017) have developed wetland trading mechanism and withdrawn farmland project to reduce the

6 damage of excessive human activities in a floodplain, which can reduce water shortage in

7 drought season. Zhang and Zhang (2020) have used a multi-objective optimization with swarm

8 intelligence approach to predict water demand and water utilization, with aim to generate an

9 effective regulation (policy) for economic, social and ecological water consumption patterns in

10 the future.

11

12 However, there are numbers of uncertainties and their interactions between human activities and

13 water resouces management, which would increase the difficulty of generating effective and

14 adaptive policies in floodplain. For example, random precipitation caused by climate change can

15 result in spatial and temporal variations (such as extreme rainfall) in water availability, which

16 can be deemed as the stochastic factors to drive floods and droughts, making net system benefits

17 fluctuation. Meanwhile, population-industry transformation into floodplain can bring about new

18 water utilization structures, which would lead varieties in water demands. Moreover, the process

19 of urbanization can damage the source function of floodplain (e.g., the capacity of soil storage,

20 the surface circulation characteristics of precipitation), which would increase the risks of flood

21 control and water shortage. Under these situations, multiple uncertainties and their interactions

22 can enhance the complexity of water resources management in a floodplain area, which requires

23 more robust manners. Therefore, a two-stage stochastic programming (TSP) has been introduced 
1 to reflect tradeoff between dynamic water demand and random water flow in a floodplain, which

2 can built a linkage between regulated policies and economic penalties based on recourse actions

3 if the pre-regulated targets are violated (Guo and Huang, 2009; Zeng et al., 2018). However, TSP

4 has difficulty in dealing with fuzzy information due to data deficit or error data acquirement.

5 Thus, a fuzzy programming (FP) can be joined to handle these fuzziness to increase the

6 expression of ambiguity (Freeze, et al., 1990; Huang and Loucks, 2000; Inuiguchi, 2012; Zeng,

7 et al., 2019). Moreover, a scenario analysis can be introduced to reflect the potential future

8 outcomes directly, which is effective to support generating effective and adaptive policies in a

9 floodplain area (Peterson, et al., 2003; Swarta, et al., 2004; Pingale, et al., 2014; Kumar et al.,

10 2016; Rong et al., 2019). Nevertheless, previous research works have few paid attention to

11 hybrid methods (e.g., TDSP, FCP and SA) into an adaptive water resource management

12 framework to deal with uncertain information for confronting adverse effects on a floodplain

13 due to population-industry transformation in Beijing-Tianjin-Hebei urban agglomeration, China

15 Therefore, the objective of this study is developing an adaptive water resource management

16 framework with combined policies (AWFP) for mitigating adverse effects and risks on a

17 floodplain due to population-industry transformation in an urban agglomeration. A

18 location-entropy based PVRA model (LE-PVRA) can be introduced to reflect the adverse effects

19 of industrial information and driven population on water resources and risks (including water

20 shortage, soil loss and flood control) into floodplain in the processes of urban agglomeration.

21 Meanwhile, a coupla-risk analysis method can be joined to reflect risks (including water shortage,

22 soil loss and flood control risks) and corrresponding correlations in risk maps. Moreover, an

23 adaptive scenario analysis based stochastic-fuzzy method (ASSF) can be embedded into an 
1 AWMF to deal with multiple uncertainties. The proposed AWFP is applied to a practical case

2 study of Yongding river floodplain region, China. The results were obtained to reflect the

3 negative effects of population-industry transformation in the context of coordination of

4 Beijing-Tianjin-Hebei urban agglomeration and corresponding damages and function

5 degradation of floodplain contemporarily. Meanwhile, the obtained results under various policy

6 scenarios (such as farmland returning to wetland, improvement of water resource utilization

7 efficiency, water diversion and flood control) can be designed to recover source function of

8 floodplain, which is effective to adjust current population-economy strategies and water

9 management patterns with a risk-averse and sustainable manner.

\section{2. Materials and methods}

\section{$13 \quad 2.1$ Case study}

15 Yongding river floodplain, with the total area of $522.65 \mathrm{~km}^{2}$, is located in the boundary of Hebei

16 province, near to Beijing and Tianjin cities, which has been undertaken the responsibility of

17 protecting the flood control safety of Beijing, Tianjin and Hebei areas. In half past century, it has

18 always been considered as an effective measure to enhance the flood storage capacity of water

19 conservancy projects and reduce the flood disaster in Beijing-Tianjin-Hebei region (BTH).

20 Meanwhile, since it is seated in semi-arid climate zone and warm temperate zone, the weather

21 condition is suitable for irrigation. Thus, more land resources have been exploited as irrigative

22 land in recent decades, which can support the pillar position of agriculture in Hebei province. 
However, in context of coordination of Beijing-Tianjin-Hebei urban agglomeration (BTHUA), numbers of backward industries have been transferred to Hebei province due to new function design of BTHUA. Under these situations, more population can be driven by industrial transformation, which would bring about negative impacts on Yongding river floodplain as follows (Men, et al., 2017): (a) industrial transformation and driven population to Yongding river floodplain can increase water demand, which would fortify water stress particular in dry season. Meanwhile, changed water use pattern due to population- industry transformation can accelerate excessive water utilization and exploitation, which would make more ecological water being occupied, leading the capacity of water resource conservation reduced. (b) persistent high population density and dense economic distribution in flood storage and detention areas can damage the function of floodplain, which would increases the risk of disaster potential loss and flood control investment. Meanwhile, the urbanization process leads to the weakening of the permeability of the underlying surface in the flood storage and detention areas, which seriously destroyed the capacity of soil storage and storage. (c) irrational irrigative scheme and excessive exploitation of water resources can lead soil erosion as the rain washed away, which would generate degeneration of source function of floodplain, leading increased water shortages, lower groundwater levels and other problems. (d) the disturbance of climate change can also increases the risk of disaster in a floodplain area, which would increase the randomness of rainfall and available water resources, leading difficulty of water resources management. Therefore, how to confront new challenges due to population-industry transformation (PIT) into floodplain would be an import issue for policymakers as follows: Firstly, how to identify the negative effects on water resource and corresponding risks based on PIT in Yongding river floodplain would be the first step for realization of damages and analysis of causes due to to excessive human activities. 
1 Secondly, how to balance the relationship between human-water in Yongding river floodplain

2 should be reconsidered, where numbers of engineering techniques (such as withdrawn farmland

3 project, wetland construction and water diversion) and policy regulations (such as

4 population-economy policy and water management pattern) would be the effective manners for

5 mitigating the damage to source function of floodplain due to PIT. Thirdly, how to deal with

6 objective and subjective uncertainties in water resource management would be a key to improve

7 the currency of water resource management with a risk-averse and robust manner.

\section{$9 \quad 2.2$ Method development}

11 In this study, an adaptive water resource management framework with combined policies (AWFP)

12 has been developed for balancing human-water relationship in floodplain in the context of

13 coordinative development of Beijing-Tianjin-Hebei urban agglomeration (CD-BTH) (as shown

14 in Figure 1). In this framework, location entropy method can be used for reflecting aggregation

15 extent of population and industry in given location (i.e., $E=\frac{I_{Z}}{G D P_{Z}} / \frac{I}{G D P}$ and $M=\frac{P_{Z}}{A R E A_{Z}} / \frac{P}{A R E A}$

16 denoted as industry and population location entropy), which can indicate the tendency of

17 population-industry transformation and mitigation based on the strategy of CD-BTH. Then,

18 PVRA model is introduced to response the effects on water resource due to PIT in Yonding river

19 floodplain area.

21 Place Figure 1 here

22 
1 Under these situations, water use pattern has been changed by industrial transformation and

2 driven population in Yonding river floodplain, which would consumed more water resource,

3 damage the capacity of soil conservation and increase the potential flood loss, enhancing various

4 risk levels in a long term (Johannes and Leeuwen, 2017). Therefore, according to current

5 population-economy scale in study region, a risk caculation system conbiming Geographic

6 Information System (GIS) can be used for reflecting various risks, which would includes various

7 indicators associated with water and soil erosion, flooding risk and water shortage. In this risk

8 caculation system, the risk of soil loss can be assessed based empirical model RUSLE (Revised

9 Universal Soil Loss Equation) based on different land use types in the Yongding River basin (e.g.,

$10 A=R \times K \times L \times S \times C \times P)($ Liu et al., 2011). Moreover, risk of water shortage can be analyzed on

11 water use patterns and land use types. However, all of these indivual risks can be influnced by

12 different objective and subjective factors, which would express as respective uncertainties.

13 Meanwhile, the traditional risk caculation system can not reflect the correlation of two risks,

14 which require an effective manner to response the correlation between different risks and

15 indicators. Thus, a Coupla function can be introduced into GIS to calculate the dependence of

16 multidimensional variables (or indicators) as following steps:

18 Step 1: Selecting the relevant indcators within different risk types, then classifying the damage

19 and risk levels as m levels.

20 Step 2: Based on $\mathrm{n}$ damage levels in $\mathrm{m}$ selected indicators, constructing one risk assessment

21 model according to characteristic value $\left(S C x_{x}, S C n_{x}, S C e_{x}\right)$, which includes assumption of the

22 upper and lower bounds of the number i level of indicator $\mathrm{X}$ as $\left(x_{i \min }, x_{i \max }\right)$ as follows: 


$$
\left\{\begin{array}{c}
S C x_{x}=\left(x_{i \min }+x_{i \max }\right) / 2 \\
S C n_{x}=\left(x_{i \min }-x_{i \max }\right) / 6 \\
S C e_{x}=s
\end{array}\right.
$$

2 Where s is a parameter; $x_{i \min }$ and $x_{i \max }$ are the upper and lower bounds of the number i level 3 of indicator $\mathrm{X}$.

4 Step 3: Selecting two random risk variable $x$ and $y$, conbiming one risk assessment model

$5\left(S C x_{x}, S C n_{x}, S C e_{x}\right)$ and $\left(S C x_{y}, S C n_{y}, S C e_{y}\right)$ into a two-dimensional risk assessment model

$6 \quad\left(S C x_{x}, S C n_{x}, S C e_{x}, S C x_{y}, S C n_{y}, S C e_{y}\right)$

$7 \quad$ Step 4: Choosing Kendall correlation coefficient method $(\tau)$ and Gini correlation

8

9

10

$$
\theta=1 / n *\left[1 /\left(1-\tau_{x y}\right)+1 /\left(1-\tau_{y z}\right)+1 /\left(1-\tau_{x z}\right)+\ldots . .\right]
$$

Step 5: Assuming indicators to follow normal distribution, the degree of dependency membership of indicators based on Coupla function can be formulated as follows:

$$
\begin{gathered}
\mu\left(x_{1}, x_{2}, \ldots x_{n}\right)=a^{*} C\left(x_{1}, x_{2}, \ldots x_{n}, \theta\right)+b * \exp \sum\left[-\left(x_{i}-S C x_{i}\right)^{2} / S C n n_{i}\right] \\
S C n n_{i}=S C n_{i}+s_{i} \\
a+b=1
\end{gathered}
$$

Where $C\left(x_{1}, x_{2}, \ldots x_{n}, \theta\right)$ is coupla function; $\mathrm{a}$ and $\mathrm{b}$ are parameters; $\exp \sum\left[-\left(x_{i}-S C x_{i}\right)^{2} / S C n n_{i}\right]$ is the degree of dependency membership of indicators.

17 Step 6: Using Coupla function into a traditional risk assessment system to reflect indivual and 
1 correlative risks, then draw a risk map.

3 Based on various risks (coulpla risk analysis) due to population-industry transformation (PIT) in

4 Yonding river floodplain, a comprenhensive plan with various policy scenarios should be

5 considered to achevie sustainability of human activities and water resource management.

6 However, in the processes of making policy decision, numbers of uncertainties (such as random

7 precipitation due to climate change, mutative water utilization demand due to population-

8 industry transformation, dynamic policy due to the coordination of BTH and fuzzy engineering

9 effects and benefits) can fortify the complexity of an AWFP issue. All above reasons can

10 increase the difficulty of generation of adaptive policies to confront the conflict between

11 population-economy development and water resource management in study region. Therefore, an

12 adaptive scenario analysis based stochastic-fuzzy method (ASSF) has been developed to handle

13 these uncertainties (as shown in Appendix 1).

14

15 Place Appendix 1 here

16

\subsection{Modeling formulation}

In study region, policymakers of floodplain are responsible for allocating water resources to

21 satisfy the demands for population-economy development in dry season; meanwhile they take

22 charge of minimizing the flood damage in flooding season. In the context of the coordination of

23 BTH, population-industry transformation into floodplain can increase expected water demand, 
1 which would exceeded what the natural system can afford in dry season, leading risks of water

2 shortage. Meanwhile, irrational water use pattern (such irrigative scheme) can damage the

3 capacity of water and soil conservation in floodplain, leading indirect environmental penalty.

4 Moreover, flood event occurrence can generate surplus water in flooding season, which would

5 result in damage and economic loss. With aim to maximize the system benefit and minimize risk

6 of system, an optimal water resource plan associated with the minimized shortage and surplus is

7 desired. Among them, various engineering techniques (such as withdrawn farmland project,

8 wetland construction and water diversion) and policy regulations (such as population-economy

9 policy and water management pattern) can be recover the source function of floodplain, which

10 are beneficial to remit water shortage in dry season and reduce the flood control as follows:

$$
\begin{aligned}
\max \text { Outcomejo }^{\not f}= & \sum_{m=1}^{M} \operatorname{pos}_{m}\left(\max _{d \in D} \text { inputA }_{m n}\right) *[(1)+(2)+(3)+(4)+(5)+(6)+(7) \\
& -(8)+(9)-(10)]
\end{aligned}
$$

$13 f \%$ is total system benefit based on an adaptive water resource management framework with

14 combined policies (AWFP) within a floodplain area, which can reflect the tradeoff between

15 population-economy development (benefits) and adverse effects (losses) based on various policy

16 scenarios in no-flooding / flooding season (¥ RMB). An adaptive scenario analysis based

17 stochastic-fuzzy method (ASSF) can be dealed with multiple uncertainties (such as fuzzy

18 informations, stochastic events and changed scenarios) in an AWFP, which displayed in

19 "Appendix 1".

20

21 (1) Benefit of expected water demand and corresponding loss of water shortage for human living $22\left(\mathrm{EBSH}_{t j}\right)$ : 
$1 \quad \sum_{t=1}^{3} \mathcal{F} F L_{t} * f l * E P L_{t}-\sum_{h=1}^{5} p_{h t} \sum_{t=1}^{3} \mathcal{L} F L_{t} * f l * S F L_{t h}$

2 (2) Benefit of expected water demand and corresponding loss of water shortage for industrial and 3 service sector $\left(E B S I_{t j}\right)$ :

4

$$
\sum_{t=1}^{3}\left(9 T_{t} * f i * E I N_{t}+\mathscr{q S E} E_{t} * f_{s} * E S E_{t}\right)-\sum_{h=1}^{5} p_{h t} \sum_{t=1}^{3}\left(\mathcal{L} q_{N_{t}} * f i * S I N_{t h}+\mathcal{L} S E_{t} * f_{s} * S S E_{t h}\right)
$$

5

6

(3) Benefit of expected water demand and corresponding loss of water shortage for agricultural sector $\left(E B S A_{t j}\right)$ :

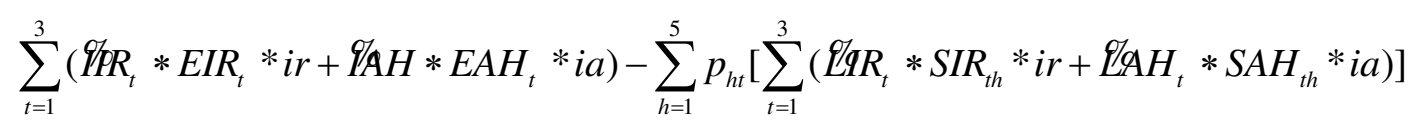

(4) Benefit of expected water demand and corresponding loss of water shortage for ecological sector $\left(E B S E_{t j}\right)$ :

$$
\sum_{t=1}^{3} \mathcal{I} E C_{t} * i e^{*} E E C_{t}-\sum_{h=1}^{5} p_{h t} \sum_{t=1}^{3} \mathcal{L E C} C_{t} * i e^{*} S E C_{t h}
$$

(5) Benefit and corresponding cost from improvement of water use efficiency through water-saving technique $\left(B I W E_{t j}\right)$ :

$$
\begin{aligned}
& \mu *\left[B F L_{t} *\left(\sum_{t=1}^{3} f l * E P L_{t}-\sum_{h=1}^{5} p_{h t} \sum_{t=1}^{3} f l * S F L_{t h}\right)+B I N_{t} *\left(\sum_{t=1}^{3} f i * E I N_{t}-\sum_{h=1}^{5} p_{h t} \sum_{t=1}^{3} f i * S I N_{t h}\right)\right. \\
& +B S E_{t} *\left(\sum_{t=1}^{3} f S^{*} E S E_{t}-\sum_{h=1}^{5} p_{h t} \sum_{t=1}^{3} f S * S S E_{t h}\right)+B I R_{t} *\left(\sum_{t=1}^{3} E I R_{t} * i r-\sum_{h=1}^{5} p_{h t} \sum_{t=1}^{3} S I R_{t h} * i r\right) \\
& \left.+B A H *\left(\sum_{t=1}^{3} I A H_{t} * i a-\sum_{h=1}^{5} p_{h t} \sum_{t=1}^{3} S A H_{t h} * i a\right)\right]-\mu *\left[\left(\sum_{t=1}^{3} C F L_{t} * f l * E P L_{t}-\sum_{h=1}^{5} p_{h t} \sum_{t=1}^{3} C F L_{t h} *\right.\right. \\
& \left.f l * S F L_{t}\right)+\sum_{t=1}^{3}\left(C I N_{t} * f i * E I N_{t}+C S E_{t} * f s * E S E_{t}\right)-\sum_{h=1}^{5} p_{h t} \sum_{t=1}^{3}\left(C I N_{t} * f i * \operatorname{SIN}_{t h}+C S E_{t} * f i * S S E_{t h}\right) \\
& \left.+\sum_{t=1}^{3}\left(C I R_{t} * E I R_{t} * i r+C A H * I A H_{t} * i a\right)-\sum_{h=1}^{5} p_{h t} \sum_{t=1}^{3}\left(C I R_{t} * S I R_{t h} * i r+C A H_{t} * S A H_{t h} * i a\right)\right]
\end{aligned}
$$




$$
\begin{aligned}
& \beta *\left[\left(\sum_{t=1}^{3} B R F L_{t} * f l * E P L_{t}-\sum_{h=1}^{5} p_{h t j} \sum_{t=1}^{3} B R F L_{t} * f l * S F L_{t}\right)+\sum_{t=1}^{3}\left(B R I N_{t} * f i * E I N_{t}+B R S E_{t} * f S * E S E_{t}\right)\right. \\
& -\sum_{h=1}^{5} p_{h t} \sum_{t=1}^{3}\left(B R I N_{t} * f i * S I N_{t h}+B R S E_{t} * f S * S S E_{t h}\right)-\beta *\left[\left(\sum_{t=1}^{3} C R F L_{t} * f l * E P L_{t}-\sum_{h=1}^{5} p_{h t} \sum_{t=1}^{3} C R F L_{t} * f l\right.\right. \\
& \left.\left.* S F L_{t h}\right)+\sum_{t=1}^{3}\left(C R I N_{t} * f i * E I N_{t}+C R S E_{t} * f_{s} * E S E_{t}\right)-\sum_{h=1}^{5} p_{h t} \sum_{t=1}^{3}\left(C R I N_{t} * f i * S I N_{t h}+C R S E_{t} * f s * S S E_{t h}\right)\right]
\end{aligned}
$$

(7) Benefit and corresponding cost from water diversion $\left(B I W R_{t j}\right)$ :

$$
\begin{aligned}
& {\left[\left(\sum_{t=1}^{3} B D F L_{t} * D P L_{t}+\sum_{t=1}^{3}\left(B D I N_{t} * D I N_{t}+B D S E_{t} * D S E_{t}\right)+\sum_{t=1}^{3}\left(B D I R_{t} * D I R_{t}+B D A H * D A H_{t}\right)\right.\right.} \\
& \left.+\sum_{t=1}^{3} B D E C_{t} * D E C_{t}\right]-\left\{\sum_{t=1}^{3} C D_{t} *\left[\left(\sum_{t=1}^{3} D P L_{t}+\sum_{t=1}^{3}\left(D I N_{t}+D S E_{t}\right)+\sum_{t=1}^{3}\left(D I R_{t}+D A H_{t}\right)+\sum_{t=1}^{3} D E C_{t}\right]\right\}\right.
\end{aligned}
$$

4 (8) Loss of soil loss from agriculture sector $\left(L B S A_{t j}\right)$ :

$\delta * L S I R_{t} *\left(\sum_{t=1}^{3} E I R_{t} * i r-\sum_{h=1}^{5} p_{h t} \sum_{t=1}^{3} \operatorname{SIR}_{t h} * i r\right)$

(9) Benefit of ecological effect for soil conservation from ecological sector $\left(B B S E_{t j}\right)$ :

$$
\sum_{t=1}^{3} \mathcal{Q E C} C_{t} * i e^{*} E E C_{t}-\sum_{h=1}^{5} p_{h t} \sum_{t=1}^{3} \mathscr{L E C} C_{t} * i e^{*} S E C_{t h}
$$

(10) Loss for flooding ( $L F F$ ):

$$
\sum_{t=1}^{3} \sum_{h=1}^{5} p_{t h} *\left(D H M_{t} * F H M_{t h}+D H I_{t} * F H I_{t h}+D H S_{t} * F H S_{t h}+D H R_{t} * F H R_{t h}+D H H_{t} * F H H_{t h}\right)
$$

The detailed nomenclatures for the variables and parameters are displayed in Appendix 2. Model (2b) presents benefit of expected water demand and corresponding loss of water shortage for human living. It means that expected water demand (i.e., first-stage variable) is satisfied, which would result in a first-stage benefit for human living; otherwise, the loss of water shortage can be generated. Since economic data is difficult to obtain as a precise value, fuzzy set can be used in Model (2b). According to the same principle, Models (2c) to (2e) present benefits of expected 
1 water demand and corresponding losses of water shortages for industrial, service, agricultural

2 and ecological sectors. In order to remit water deficit in dry season, technique improvement

3 (including water use efficiency through water-saving technique and water duplication through

4 water recycling technology) and water diversion can be considered, which can bring about

5 economic benefits to remit water-shortage losses, but generating costs (as shown in Models (2f)

6 to (2h)). Meanwhile, excessive agricultural actvitivies (such as irrgation) would enhance water

7 and soil loss, leading losses in Model (2i). However, it can be remitted by ecological effect (such

8 as wetland construction), which would bring about ecologial benefits (as shown in Model (2j)).

9 Nevertheless, in flooding season, surplus water would damage human base setting and irrigative

10 land, which would result in losses in flooding seasons (as shown in Model (2k)). Under these

11 situations, numbers of constraints associated with available land resources, water availabilities,

12 population development scales, irrigative production scales, livestock breeding scales and the

13 capacities of technique improvement can be considered as follows:

(1) Constraints of available water resources:

16

$$
\begin{aligned}
& \operatorname{Cr}\left\{\sum_{t=1}^{3} \sum_{h=1}^{5} V_{t h}^{O}=\sum_{t=1}^{3} \sum_{h=1}^{5}\left(\beta_{t h}^{o}-H_{t}-G_{t}\right)\right\} \geq \alpha \\
& \operatorname{Cr}\left\{\left[\sum_{t=1}^{3} I F L_{t} * f l * E P L_{t}-\sum_{h=1}^{5} p_{h t} \sum_{t=1}^{3} L F L_{t} * f l * S F L_{t h}\right]+\left[\sum_{t=1}^{3}\left(I I N_{t} * f i * E I N_{t}+I S E_{t} * f s * E S E_{t}\right)\right.\right. \\
& \left.-\sum_{h=1}^{5} p_{h t} \sum_{t=1}^{3}\left(L I N_{t} * f i * S I N_{t h}+L S E_{t} * f i * S S E_{t h}\right)\right]+\left[\sum_{t=1}^{3}\left(I I R_{t} * E I R_{t} * i r+I A H * E A H_{t} * i a\right)-\right. \\
& \left.\sum_{h=1}^{5} p_{h t} \sum_{t=1}^{3}\left(L I R_{t} * S I R_{t h} * i r+L A H_{t} * S A H_{t h} * i a\right)\right]+\left[\sum_{t=1}^{3} I E C_{t} * i e^{*} E E C_{t}-\right. \\
& \left.\left.\sum_{h=1}^{5} p_{h t} \sum_{t=1}^{3} L E C_{t} * i e^{*} S E C_{t h}\right] \leq V_{t h}^{O /}\right\} \geq \alpha
\end{aligned}
$$

(2) Constraints of available land resources: 
1

$$
\left[\sum_{t=1}^{3}\left(E I R_{t}+E A H_{t}\right)-\sum_{h=1}^{5} p_{h t}\left[\sum_{t=1}^{3}\left(S I R_{t h}+S A H_{t h}\right)\right]+\left(\sum_{t=1}^{3} E E C_{t}-\sum_{h=1}^{5} p_{h t} \sum_{t=1}^{3} S E C_{t h}\right) \leq L R_{t}\right.
$$

2 (3) Constraints of population development scales:

3

$$
S M_{t}^{\min } \leq \sum_{t=1}^{3}\left(E P L_{t}+E I N_{t}+E S E_{t}\right) \leq S M_{t}^{\max }
$$

4 (4) Constraints of irrigative production scales:

$$
S D_{t}^{\min } \leq \sum_{t=1}^{3} E I R_{t} \leq S D_{t}^{\max }
$$

(5) Constraints of livestock breeding scales:

$$
S I_{t}^{\min } \leq \sum_{t=1}^{3} E A H_{t} \leq S I_{t}^{\max }
$$

(6) Constraints of capacity of water recycling:

$$
\beta *\left[\sum_{t=1}^{3} f l * E P L_{t}+\sum_{t=1}^{3}\left(f i * E I N_{t}+f s^{*} E S E_{t}\right)\right] \leq S C_{t}^{\max }
$$

(7) Constraints of capacity of water-saving:

$$
\mu *\left[\left(\sum_{t=1}^{3} f l * E P L_{t}+\sum_{t=1}^{3}\left(f i * E I N_{t}+f S * E S E_{t}\right)+\sum_{t=1}^{3}\left(E I R_{t} * i r+I A H_{t} * i a\right)\right] \leq C P_{t}^{\max }\right.
$$

(8) Constraints of economic benefits and losses:

$$
I F L_{t} \geq L F L_{t}, I I N_{t} \geq I S E_{t}, L I N_{t} \geq L S E_{t}, I I R_{t} \geq L I R_{t}, I A H_{t} \geq L A H_{t}, I E C_{t} \geq L E C_{t}
$$

(9) Non-negative constraints:

5

$$
\begin{aligned}
& I F L_{t}, L F L_{t}, I I N_{t}, I S E_{t}, \operatorname{LIN}_{t}, L S E_{t}, I I R_{t}, L I R_{t}, I A H_{t}, L A H_{t}, I E C_{t}, L E C_{t} \geq 0 \\
& E P L_{t}, S F L_{t h}, E I N_{t}, E S E_{t}, \operatorname{SIN}_{t h}, S S E_{t h}, E I R_{t}, E A H_{t}, S I R_{t h}, S A H_{t h}, E E C_{t}, S E C_{t h} \geq 0
\end{aligned}
$$

Model (3a) shows constraint of water availability based on regional water carrying capacity, which can be calculated as total availabilities (including surface and underground water) minus 
1 evaporation / infiltration loss of water from river, normal water requirement of watercourse $\left(\mathrm{m}^{3}\right)$

2 (Zeng et al., 2019). Water avilability can be impacted by rainfall strongly in dry and wet seasons,

3 which presents as stochastice chararcters. Model (3b) presents water shortage based on recourse

4 actions to expected demands when random water availibility occur in flooding and non-flooding

5 seaseons. Model (3c) displays allocated land area based on farmland returning to wetland, where

6 the transferred land resources should not be greater than total land scale minus living and

7 industrial land (equal to $L R_{t}$ ). Models (3d) to (3f) demonstrate constraint of current

8 population-economy development scale due to population-industry transformation into

9 floodplain in context of coordination of BTH. Models (3g) to (3h) demonstrate the capacity of

10 water-saving technique and water retreatment technology. Models (3i) to (3k) present the

11 relationship between economic benefit and loss relationships; meanwhile, non-negative

12 restrictions have displayed at end of constraints.

142.4 Data acquirement

16 Table 1 shows the economic data as fuzzy sets, which is calculated by expert evaluation method 17 according to regional statistical yearbooks, with consideration of social-economic development

18 (SYH, 2006-2016; WRH, 2006-2016). Meanwhile, various water availability levels due to

19 random rainfall can be divided into five levels (i.e., very low, low, medium, high and very high

20 levels), which corresponding probabilities would be $0.1,0.2,0.4,0.2$ and 0.1 simulated by

21 previous precipitation from 2005 to 2018 (SYH, 2006-2016; WRH, 2006-2016). In addition, in

22 order to reduce water shortage in dry season and flood risk in flooding season, various policy

23 scenarios can be designed in Table 2 as follows: (a) scenario 0 (S0) is the basic scenario present 
1 current population-industry development and water resources management. (b) various

2 individual policies (including improvement of water resource utilization efficiency, water

3 diversion, farmland returning to wetland) can be considered. Among them, scenario 1 to 4 (S1 to

4 S4) display the policies with improvement of water use efficiency by prompting water saving

5 and recycling ratio $(0 \%, 5 \%$ and $15 \%)$. Scenario 5 to 6 (S5 to S6) show that farmland returning

6 to wetland, where the constructed wetland would be 2 and 4 times than the area under S0.

7 Scenarios 7 to 8 (S7 to S8) present policies associated with water diversion to remit water

8 shortages. (c) scenarios 9 to 12 present mixed policies based on S1 to S8.

9

$10 \quad$ Place Tables 1 to 2 here

11

13 3. Result and discussion

143.1 Adverse effects and risks of floodplain due to population-industry transformation under basic

15 scenario $(\mathrm{SO})$

16 3.1.1 Adverse effects on water resources in Yongding river floodplain due to population-industry

17 transformation

18 Figure 2 presents the location entropy of population-industry in Beijing-Tianjin-Hebei region

19 from 2002 to 2019, which can reflect the tendency of population-industry transformation and

20 mitigation based on the strategy of coordinative development of Beijing-Tianjin-Hebei urban

21 agglomeration. The results present that the location entropy of agriculture in Beijing and Tianjin

22 is decreasing, but increasing in Hebei. Meanwhile, the location entropy of industry in Tianjin and

23 Hebei province would increase. Based on industrial transformation, the population concentration 
1 in Beijing and Tianjin would be higher than Hebei province from 2002 to 2014. However, the

2 entropy of population in Hebei province would increase from 2015, which indicate that the

3 driven effect of industrial transformation would increase population concentration in Hebei

4 province. Under these population-industry transformation situations, the effects of

5 population-industry transformation on water resource management in Yongding river floodplain

6 of Hebei province have been obtained through PVRA model (as shown in Tables 3 to 4). Before

7 analyzing the time series variables, the stability of the data has been checked by ADF test (in

8 Table 3), which indicated that all the indicators are stationary time series data, meeting the

9 preconditions of model estimation, impulse response and variance decomposition. Meanwhile,

10 according to the test results of AIC, SBIC and HQIC under different lag orders, the result

11 indicate that the optimal lag period of the model is determined as 3 periods. Table 4 displays that

12 the transfer of the industry in floodplain can significantly promote the growth of the gross

13 regional product (GDP) and average GDP per person, both at the level of 5\%, but at the same

14 time, it will also lead to the increase of water demand, which is at the level of $1 \%$. From the

15 point of parameter selection, in the case of other conditions unchanged, the industry in floodplain

16 city transfer, each additional unit can promote regional GDP rose 0.019 unit, increase water

17 demand 0.046 units, which should attract attention to water saving technology improvement.

18 However, service industry transformation has a positive impact on regional economic growth,

19 but increase more water demand than industry.

$21 \quad$ Place Figure 2 and Tables 3 to 4 here

22 
2 Figure 3 presents risks of water shortage, soil loss and flood control based on current

3 population-industry scale in period 1 under $\mathrm{S} 0$ when $\alpha$ is 0.6 . Based on current

4 population-industry scale (under S0) in Yonding river floodplain, various water shortages would

5 occur when $\alpha$ is 0.6 , which indicates that the water demand for current population-industry scale

6 can be met hardly in dry seasons, leading higher water shortages; vice versa. Meanwhile, the

7 irrigation would be the highest water shortage sector, which results in a highest water-shortage

8 area than the area in landscape and wetland protection. Moreover, in comparison of water

9 shortages for various human activities, the highest water shortage for population is human living

10 (denoted as "HL") comparing to industrial and service population.

11

\subsection{Adaptive water resources management under various policy scenarios}

\subsubsection{Water shortages and allocations under individual policy scenarios (S1 to S8)}

\subsubsection{Improvement of water resource utilization efficiency (S1 to S4)}

In order to remit water shortage in human activities, technique improvement (improvement of water saving and recycling) can considered in S1 to S4, which can displays total water shortages among various water use sectors when $\alpha$ is 0.6 (as shown in Figure 4). The results present that improvement of water saving could prompt water utilization efficiencies, which can generate lower water shortages particular in wet season (when water flow is low). As the same principle, water shortages could be reduced by improvement of water recycling ratio. For example, the 
1 water shortage would be $77.23 \times 10^{3} \mathrm{~m}^{3}$ and $48.34 \times 10^{3} \mathrm{~m}^{3}$ under $\mathrm{S} 1$ and $\mathrm{S} 4$ when water flow

2 is low. Although improvement of water saving and recycling can be deemed as effective manners

3 to reduce water shortage, high cost of generalization would be a big challenge for policymaker in

4 Yonding river floodplain.

5

6 Place Figure 4 here

7

8

$9 \quad$ 3.2.2.2 Farmland returning to wetland (S5 to S6)

10 In order to reduce the greatest water shortage in irrigation and improve the water / soil

11 conservation in study region, the farmland returning to wetland (CFW) project can be

12 encouraged to improve source functions of floodplain due to overdeveloped irrigation. Figure 5

13 presents water shortages and corresponding shortage ratios between irrigation and wetland with

14 consideration of withdrawn farmland to wetland (S5 to S6) when $\alpha$ are 0.6 and 0.99 . In this

15 region, the CFW can reduce water demand for irrigation, which can drop its shortage ratio in the

16 long run. However, wetland construction require water resources, thus, the reduction of water

17 shortage by CFW is limited. For instance, CFW can reduce shortage ratio of irrigation would be

$187.23 \%$ at highest when water flow is low in period 1. Meanwhile, CFW can improve source

19 function of floodplain due to wetland construction, which would prompt the risk control in

20 flooding season. Thus, CFW can be deemed as an effective manner to remit water shortage and

21 control flood risk contemporarily, but which would reduce direct economic income of irrigation

22 in the short run.

23 
$4 \quad$ 3.2.2.3 Water diversion (S7 to $S 8$ )

6 Figure 6 shows optimal water allocations with consideration of water diversion (S7 to S8) when

$7 \quad \alpha$ are 0.6 and 0.9 . In comparison of various water use sectors, irrigation would be allocated

8 greatest water resources, which indicated that the agricultural sector would be the key industry in

9 study region. However, backward irrigative scheme would low efficiency in agricultural, which

10 would result in a higher water deficit when water flow is low. Water diversion (e.g. South-North

11 water transfer project) can be considered to remit water deficit in study region, which would

12 improve the satisfaction rate of optimal water allocation. For example, the optimal water

13 allocation would be $315.43 \times 10^{3} \mathrm{~m}^{3}$ and $378.25 \times 10^{3} \mathrm{~m}^{3}$ under $\mathrm{S} 7$ and $\mathrm{S} 8$ when water flow is

14 low in period 1, which would be better than the situation under S1.

15

16 Place Figure 6 here

17

3.2.2 Water shortages and flood controls under combined scenarios (SO to S12)

21 Figure 7 shows water shortages and flood controls under S0 to S12 when $\alpha$ are 0.6 and 0.9. The

22 results display that the effect of mixed policies would be better than individual one. For instance,

23 the water shortage under S0, S2, S4, S6 and S8 (individual policies) would be greater than that 
1 under S10 and S12 (mixed policies); meanwhile, surplus water under S8 (individual policies)

2 would be bigger than that under S10 and S12 (mixed policies). In addition, in comparison of

3 various scenarios, S6 has an advantage of flood control, but which has little ability to reduce

4 water shortage. The effect of water shortage reduction under S4 and S8 would be best among

5 various scenarios.

6

$7 \quad$ Place Figure 7 here

8

9

10 3.2.3 Coupla risks of water shortage, soil loss and flood control under various scenarios (SO to

$11 \quad S 12)$

12

13 Figure 8 displays coupla risks of water shortage, soil loss and flood control under S0 to S12

14 when $\alpha$ is 0.6 . The results present that technique improvement ( 2 2 and S4) would decrease risks

15 of water shortage to a extent, but which would hardly reduce risks of soil loss and flood control.

16 Meanwhile, water diversion (S8) would reduce risk of water shotage at a highest level, but which

17 would increase risks of soil loss and flood control. Morvere, withdrawn farmland to wetland (S6)

18 is effective to reduce risks of soil loss and flood control, but which requires more water resources,

19 leading a raised water-shortage risk. In comparision, the combined policy (S12) has advantage of

20 reducing risk of water shortage and corresponding (or coupla) risks soil loss and flood control

21 than other individual policies (S2, S4, S6 and S8).

22

23 Place Figure 8 here 
5 Figure 9 displays system benefits under S1 to S12 when $\alpha$ are 0.6 and 0.9 . The results present as

6 follows: (a) based on population-industry transformation from Beijing or Tianjin to Hebei, the

7 water resource carrying capacity can not afford current water use pattern, which can increase the

8 loss of water shortages, leading a lower system benefit (S1). (b) The current technical level can

9 only support water-saving and recycling techniques increased by $9 \%$ at highest (under S3),

10 which would bring about an increased system benefit; otherwise, it would generate a dropped

11 benefit (under S4) due to excessive cost of technical improvement and popularization. (c)

12 although CFW can bring about a higher benefit in a long run, lower direct economic incomes

13 from wetland construction would generate lower benefits in the short run (S5 and S6). (d) Since

14 the cost of water diversion is relative low for floodplain in the context of the south-to-north water

15 diversion project funded by the state, it can remit the losses of water shortage for current

16 population-economy pattern in the mass, which would bring about higher benefits (S7 and S8).

17 (e) a comprehensive combined policy (including improvement of technique, CFW, water

18 diversion) would bring about better results for water shortage reduction, which can lead higher

19 benefits (S9 to S12). (f) The results show that system benefit would decrease by a raised $\alpha$ level, 20 which indicates that a lower reliability level would lead a higher benefit. 


\section{Conclusions}

4 Therefore, this study can be expressed as follows: (a) an adaptive water resource management

5 framework with combined policies (AWFP) is developed for mitigating adverse effects on water

6 stress in floodplain due to population-industry transformation (PIT) in the process of urban

7 agglomeration. (b) A location-entropy based PVRA model and coupla-risk analysis can be

8 introduced to reflect the adverse effects of industrial information and driven population on water

9 resources and corresponding risks (including water shortage, soil loss and flood control) and

10 their correlations in a floodplain area in the processes of urban agglomeration. (c) an adaptive

11 scenario analysis based stochastic-fuzzy method (ASSF) can be embedded into an AWMF to deal

12 with multiple uncertainties. (d) The proposed AWMF is applied to a practical case study of

13 Yongding river floodplain region for confronting adverse effects due to population-industry

14 transformation into floodplain in the context of coordination of Beijing-Tianjin-Hebei urban

15 agglomeration, China.

16

17 With the aid of the AWMF in Yongding river floodplain, numbers of discoveries can be

18 displayed as follows: (a) "strategy of Beijing-Tianjin-Hebei coordinated development" (from

19 2013) has accelerated the population-industry transformation (PIT) into floodplain. Although PIT

20 can support economic development in Yonding river floodplain, excessive exploitation and

21 construction would destroy the source function of floodplain, increasing the risk of water

22 shortage, soil loss and flood control. Ecological protection project (such as farmland returning to

23 wetland) is effective manner to recover the source function of floodplain, but which has been not 
1 attached importance in study region. (b) backward irrigative scheme and low water utilization

2 efficiency are not accommodate to regional water carrying capacity (i.e., shrunk water

3 availability and uneven rainfall) in Yonding river floodplain, which would require a more

4 effective and adaptive water resource use pattern to remit current water crisis. (c) individual

5 policies (such as improvement of water resource utilization efficiency, water diversion, farmland

6 returning to wetland) have their own advantages of water shortage reduction or flood risk control

7 respectively, but which have limitations of the high cost of generalization and direct income

8 reduction in a short-term. Thus, how to balance the tradeoff between benefit and cost in a long

9 run can be challenges for regional policymakers.

11 Therefore, various specific suggestions can be summarized as follows: Firstly, regulation of PIT

12 into floodplain according to source function of floodplain should be considered to reduce its

13 negative effects and risks of water shortage, soil loss and flood control. Meanwhile, limitation of

14 land overexploitation and excessive construction should be advocated for releasing the conflict

15 between human activities and water stress in Yongding river floodplain. Secondly, more cleaner

16 production mode and water-saving pattern should be introduced into water resources

17 management in floodplain, which can remit water crisis from water-use side. Thirdly,

18 policymakers should analyze the tradeoff between economic benefits and costs of various policy

19 scenarios not just in the short term, but in the long term, with aim to generate combination of

20 mixed policies to maximize positive effects due to PIT, minimizing risks to the great extent.

21 Meanwhile, the policymakers should step up guidance to technique improvement, increase

22 investment to water diversion project, and strengthen population and industrial planning, which

23 could support the adjustment of regional strategies associated with population growth, industrial 
1 layout, water resource use pattern and floodplain function protection sustainably.

2

3 Ethical Approval: There is no Ethical Approval in this paper (Not applicable).

4

5 Author Contributions: Xueting Zeng has constructed the idea of paper and formulated the

6 framework of AWFP; Junlong zhang has formulated models and designed scenarios; Jia Liu has

7 drawn the risk maps in this paper.

8

9 Consent to Participate and publish: All authors have agreed to participate and publish this

10 paper after acceptance.

11

12 Funding: This research was supported by the National Natural Science Foundation of China

13 (42007412), National Science and Technology Major Project of China (Grant No.

14 2018ZX07105-002) and National Natural Science Foundation of China (51809145).

15

16 Competing Interest: The authors declare no conflict of interest.

17

18 Availability of data and materials: The data sources have been put into Mendeley Data (DOI:

$19 \quad 10.17632 / \mathrm{c} 45776 \mathrm{hm} 2 \mathrm{w} .1)$.

20

21 


\section{References}

4 Freer, J.E., Mcmillan, H., Mcdonnell, J.J., Beven, K.J., 2004. Constraining dynamic TOPMODEL responses for imprecise water table information using fuzzy rule based performance measures. J Hydro 291: 254-277. http://doi.org/10.1016/j.jhydrol.2003.12.037.

Guo, P., Huang, G.H., 2009. Two-stage fuzzy chance-constrained programming: application to water resources management under dual uncertainties. Stoch Env Res Risk A 23: 349-359. http://doi.org/10.1007/s00477-008-0221-y.

Horta, I.M., Camanho, A.S., Dias, T.G., 2016. Residential building resource consumption: A comparison of Portuguese municipalities' performance. Cities 50: 54-61. http://doi.org/10.1016/j.cities.2015.08.009.

Huang, G.H., Loucks, D.P., 2000. An inexact two-stage stochastic programming model for water resources management under uncertainty. Civ Eng Environ Syst 17: 95-118. http://doi.org/10.1080/02630250008970277.

Inuiguchi, M., 2012. Robust optimization by fuzzy linear programming. Lect Note in Econ Math Syst 658: 219-239. http://doi.org/10.1007/978-3-642-22884-1_11.

Johannes, C., Leeuwen, V., 2017. Water governance and the quality of water services in the city of Melbourne. Urban Water J 14: 247-254. https://doi.org/10.1080/1573062X.2015.1086008.

Knox, J.C., 2006. Floodplain Sedimentation in the Upper Mississippi Valley: Natural Versus Human Accelerated. Geomorphology 79: 286-310. https://doi.org/10.1016/j.geomorph.2006.06.031

Kumar, V., Vasto-Terrientes, L.D., Valls, A., Schuhmacher, M., 2016. Adaptation strategies for 
water supply management in a drought prone Mediterranean river basin: Application of outranking method. Sci Total Environ 540: 344-357. http://doi.org/10.1016/j.scitotenv.2015.06.062.

Liu, C.M., 2003. An analysis of the relationship between water resources and population-economy-society-environment. J Nat Res 18: 635-644. https://doi.org/10.11849/zrzyxb.2003.05.017.

Liu, W., Xu Y., Huang Y., 2011. Effects of global warming on precipitation and run- off volume in Xinjiang. Arid. Geog., 34, 419-428, https://doi.org/10.1007/s10409-004-0010-x.

Men, B., Liu, H., Tian, W., Liu, H., 2017. Evaluation of sustainable use of water resources in Beijing based on rough set and fuzzy theory. Water 9: 852. http://doi.org/10.3390/w9110852.

Olsen, J.R., Beling, P.A., Lambert, J.H., 2000. Dynamic models for floodplain management. J Water. Res Pl ASCE 126: 167-171. https://doi.org/10.1061/(ASCE)0733-9496(2000)126:3(167).

Peterson, G.D., Graeme, S.C., Stephen, R.C., 2003. Scenario planning: a tool for conservation in an uncertain world. Conserv Biol 17: 358-366.

https://doi.org/10.1046/j.1523-1739.2003.01491.x.

Pingale, S.M., Jat, M.K., Khare, D., 2014. Integrated urban water management modelling under climate change scenarios. Res Conserv Recy 83: 176-189. https://doi.org/10.1016/j.resconrec.2013.10.006.

Rong, Q., Cai, Y., Su, M., Yang, Z., 2019. Identification of the optimal agricultural structure and population size in a reservoir watershed based on the water ecological carrying capacity under uncertainty. J Clean Prod 234: 335-343. https://doi.org/10.1016/j.jclepro.2019.06.179 Simmons, B., Woog, R., Dimitrov, V., 2007. Living on the edge: a complexity-infomed 
exploration of the human-water relationship. World Fut 63: 275-285. https://doi.org/10.1080/02604020601174927.

Sanon, S., Hein, T., Douven, W., Winkler, P., 2012. Quantifying ecosystem service trade-offs: the case of an urban floodplain in Vienna, Austria. J Environ Manag 111: 159-172. https://doi.org/10.1016/j.jenvman.2012.06.008.

Swarta, R.J., Raskinb, P., Robinsonc, J., 2004. The problem of the future: sustainability science and scenario analysis. Global Environ Chang 14:137-146. https://doi.org/10.1016/j.gloenvcha.2003.10.002.

The statistical yearbook of Hebei province (SYH) 2006-2016. China. 2007-2017.

The water resources report of Hebei Province (WRH) 2006-2016. China. 2007-2017.

Zeng, X.T., Li, Y.P., Huang, W., Bao, A.M., Chen, X., 2014. Two-stage credibility-constrained programming with Hurwicz criterion (TCP-CH) for planning water resources management. Eng Appl Artif Intell 35: 164-175. https://doi.org/10.1016/j.engappai.2014.06.021.

Zeng, X.T., Yang, X.L., Yu, L.Y., Chen, H.L., 2015. A mix inexact-quadratic fuzzy water resources management model of floodplain (IQT-WMMF) for regional sustainable development of Dahuangbaowa, China. Water 7: 2771-2795. http://doi.org/10.3390/w7062771.

Zeng, X.T., Zhao, J.Y., Yang, X.L., Wang, X., Xu, C.W., Cui, L., Zhou, Y., 2017. A land-indicator-based optimization model with trading mechanism in wetland ecosystem under uncertainties. Ecol Indic. 74: 279-299. http://doi.org/10.1016/j.ecolind.2016.11.011.

Zeng, X.T., Li, Y.P., Huang, G., 2019. Scenario analysis of a water-food nexus optimization with consideration of population-economy regulation in Beijing-Tianjin-Hebei region. J Clean Prod 228: 927-940. 
1 Zhang, F., Zhang, Y., 2021. A multi-objective optimization prediction approach for water 2 resources based on swarm intelligence. Earth Sci Inform 14: 1-12.

3 http://doi.org/10.1007/s12145-020-00521-1.

4 
3 In a real water resources management issue, a two-stage stochastic programming (TSP) can be

4 introduced to conduct a linkage between expected demand target and random supply capacity as

5 follows:

$6 \quad \operatorname{Max} f=u w-\sum_{h=1}^{r} p_{h} q\left(v, \delta_{h}\right)$

$7 \quad$ s.t. $\quad R\left(\delta_{h}\right) w+S\left(\delta_{h}\right) v=g\left(\delta_{h}\right), \quad \delta_{h} \in \Omega$

8

9

10

11

12 In Model (A-1), the first-stage decisions ( $u w)$ can be rectified by second-stage cost function (i.e.,

$\left.13 \sum_{h=1}^{r} p_{h} q\left(v, \delta_{h}\right)\right)$, when second-stage decision variable variables (i.e., $v$ ) occur. where $p_{h}$ is

14 possibility of random event occurrence; $u$ is coefficient parameter; $w$ is the first-stage

15 decision variable (Huang and Loucks, 2000; Li et al., 2009). However, various fuzzy information

16 can not be handled by TSDP with probabilistic distributions (Doolse et al., 2010; Zeng et al.,

17 2017). Therefore, a fuzzy credibility constrained programming (FCP) can be joined into TSDP as

18 follows:

19

$$
C r\{a w \leq B / \geq \alpha
$$

20

21 Based on concept of fuzzy credibility, the credibility measure $(\mathrm{Cr})$ can be expressed as 
$1 \operatorname{Cr}\{\varsigma \leq s\}=\frac{1}{2}(\operatorname{Pos}\{\varsigma \leq s\}+\operatorname{Nec}\{\varsigma \leq s\})$ (Inuiguchi 2012). In general, credibility level should be

2 greater than 0.5 usually (Tanaka and Zimmermann, 2000; Zeng et al., 2017). Thus, the Model

3 (A-2a) can be proven as follows:

$4 \quad \operatorname{Cr}\{g \propto s\} \geq \alpha \Leftrightarrow s \leq(2-2 \alpha) \varsigma_{2}+(2 \alpha-1) \varsigma_{1} \Leftrightarrow s \leq \varsigma_{2}+(1-2 \alpha)\left(\varsigma_{2}-\varsigma_{1}\right)$

6 In general, credibility of satisfying $\% s$ should be bigger than / equal to credibility level $\alpha$, 7 where credibility level should be greater than 0.5 usually (Zeng et al., 2015). Thus, the Model

$8 \quad(\mathrm{~A}-2 \mathrm{~b})$ can be proven credibility measure when $\alpha>0.5$ :

$9 \quad a w \leq c_{n}^{2}+(1-2 \alpha)\left(c_{n}^{2}-c_{n}^{1}\right)$.

11 Thus, a fuzzy-stochastic method (FS) can be resolved as follows:

12

13

14

15

16

17

18

19

20

21

$$
\operatorname{Max} f=u w-\sum_{h=1}^{r} p_{h} q\left(v, \delta_{h}\right)
$$

$$
\text { s.t. } \quad R\left(\delta_{h}\right) w+S\left(\delta_{h}\right) v=g\left(\delta_{h}\right), \quad \delta_{h} \in \Omega
$$

$$
a w \leq c_{n}^{2}+(1-2 \alpha)\left(c_{n}^{2}-c_{n}^{1}\right)
$$

$$
w \geq 0
$$$$
v \geq 0
$$

(n)

$v \geq 0$ 
2 Where Outcome $\left(B_{m n}\right)$ is the decision outcome;; pos ${ }_{m}$ is probability of each scenario

3 occurrence; $\mathrm{d}$ is the option, D is the options area, $A_{m n}\left(A_{n} \in A, \quad n=1,2, \ldots, N\right)$ is the overall

4 performance of various policy scenarios, which means that expected target with different

5 attitudes. Therefore, an adaptive scenario analysis based stochastic-fuzzy method (ASSF) can be

6 formulated as follows:

$7 \quad \max \operatorname{Outcome}\left(B_{m n}\right)=\sum_{m=1}^{M} \operatorname{pos}_{m}\left(\max _{d \in D} \operatorname{inputA} A_{m n}\right) *\left[u w-\sum_{h=1}^{r} p_{h} q\left(v, \delta_{h}\right)\right]$

$8 \quad$ s.t. $\quad R\left(\delta_{h}\right) w+S\left(\delta_{h}\right) v=g\left(\delta_{h}\right), \quad \delta_{h} \in \Omega$

$9 \quad a w \leq c_{n}^{2}+(1-2 \alpha)\left(c_{n}^{2}-c_{n}^{1}\right)$

$10 \quad w \geq 0$

$11 v \geq 0$

12 


\section{Subscript}

$\mathrm{t} \quad$ Planning period: $\mathrm{t}=1$ period $1, \mathrm{t}=2$ period $2, \mathrm{t}=3$ period 3 ;

$\mathrm{h}$ Water flow level: $\mathrm{h}=1$ very low level, $\mathrm{h}=2$ low level, $\mathrm{h}=3$ medium level, $\mathrm{h}=4$ high level, $\mathrm{h}=5$ very high level;

\section{$5 \quad$ Notation}

$I F L_{t}$,

$\mathrm{EFL}_{t}$

$f l$

$L F L_{t}$

$I I N_{t}, I S E_{t}$

$\operatorname{EIN}_{t}, \mathrm{ESE}_{t}$

$f i, f s$

$\operatorname{LIN}_{t}, L S E_{t}$
Total system benefit (¥ RMB)

Net benefit of human living per volume of water being delivered in period $\mathrm{t}\left(¥ \mathrm{RMB} / \mathrm{m}^{3}\right)$

Expected population living in floodplain in period $t$ (person)

The water consumption per capita for urban and rural population in period $\mathrm{t}\left(\mathrm{m}^{3} /\right.$ person $)$

Loss of water shortage for urban and rural population per volume of water not being delivered in district $\mathrm{j}$ in period $\mathrm{t}\left(¥ \mathrm{RMB} / \mathrm{m}^{3}\right.$ ) Net benefit of water for industrial plants and service plants per volume of water being delivered in period $\mathrm{t}\left(¥ \mathrm{RMB} / \mathrm{m}^{3}\right)$ Expected population for industrial plants and service plants in period $\mathrm{t}$ (person)

The water consumption per capita for industrial and service population in period $\mathrm{t}\left(\mathrm{m}^{3} /\right.$ person)

Loss of water shortage for industrial and service population per 
volume of water not being delivered in district $\mathrm{j}$ in period $\mathrm{t}$ $\left(¥ \mathrm{RMB} / \mathrm{m}^{3}\right.$ )

$I I R_{t}, I A H_{t}$

$E I R_{t}$,

$E A H_{t}$

ir ,

ia

$L I R_{t}, I A H_{t}$

$I E C_{t}$

$E E C_{t}$,

ie

$L E C_{t}$

$S F L_{t h}, S I N_{t h}, S S E_{t h}$,

$S I R_{t h}, S A H_{t h}, S E C_{t h}$

$B F L_{t}, B I N_{t}, B S E_{t}$,
Net benefit of water for irrigation and livestock production per

volume of water being delivered in period $\mathrm{t}\left(¥ \mathrm{RMB} / \mathrm{m}^{3}\right)$

Expected irrigative area in period t (ha)

Expected population of livestock in period $\mathrm{t}$ (head)

The water consumption per capita for irrigative area in period $\mathrm{t}\left(\mathrm{m}^{3} /\right.$ ha)

The water consumption per capita for livestock production in period $\mathrm{t}\left(\mathrm{m}^{3} /\right.$ head $)$

Loss of water shortage for irrigation and livestock production per volume of water being delivered in period t $\quad$ (¥ $\mathrm{RMB} / \mathrm{m}^{3}$ )

Net benefit of water for wetland per volume of water being delivered in period $\mathrm{t}\left(¥ \mathrm{RMB} / \mathrm{m}^{3}\right.$ )

Expected wetland area in period $\mathrm{t}(\mathrm{ha})$

The water consumption per capita for wetland in period $\mathrm{t}\left(\mathrm{m}^{3} / \mathrm{ha}\right)$

Loss of water shortage for ecological sector (wetland) per volume of water being delivered in period $\mathrm{t}\left(¥ \mathrm{RMB} / \mathrm{m}^{3}\right.$ )

Water shortage for human living, industrial sector, service sector, irrigation and livestock production and ecological protection per volume of water being not delivered in period $\mathrm{t}\left(¥ \mathrm{RMB} / \mathrm{m}^{3}\right)$

Net benefit from water saving technique for human living, 
$B I R_{t}, B A H_{t}$

$\mu$

$\beta$

$B D F L_{t}, B D I N_{t}$,

$B D S E_{t}, B D I R_{t}$,

$B D A H_{t}, B D E C_{t}$

$D F L_{t}, D I N_{t}, D S E_{t}$,

$D I R_{t}, D A H_{t}, D E C_{t}$

$C D_{t}$

$\operatorname{LSIR}_{t}$

$\delta$

$C P_{t}^{\max }$

$S C_{t}^{\max }$

$C F L_{t}, C I N_{t}, C S E_{t}$,

$\mathrm{CIR}_{t}, \mathrm{CAH}_{t}$ industrial sector, service sector, irrigation and livestock production in period $\mathrm{t}\left(¥ \mathrm{RMB} / \mathrm{m}^{3}\right.$ )

$B R F L_{t}, B R I N_{t}, B R S E_{t}$, Net benefit from water recycling technique for human living, industrial sector and service sector in period $\mathrm{t}\left(¥ \mathrm{RMB} / \mathrm{m}^{3}\right.$ )

The improvement ratio of saving technique

The recycling ratio of water duplication

Net benefit from water diversion for human living, industrial sector, service sector, irrigation, livestock production and ecological protection in period $\mathrm{t}\left(¥ \mathrm{RMB} / \mathrm{m}^{3}\right.$ )

Amount of water diversion of floodplain in period $\mathrm{t}\left(\mathrm{m}^{3}\right)$

The cost of water diversion of floodplain in period $\mathrm{t}\left(¥ \mathrm{RMB} / \mathrm{m}^{3}\right.$ ) Loss of soil loss from agriculture sector per volume of water being delivered in period $\mathrm{t}\left(¥ \mathrm{RMB} / \mathrm{m}^{3}\right)$

The ratio of soil loss of agriculture sector

The maximal capacity of water saving technique

The maximal capacity of retreatment technology

The cost of water saving technique for human living, industrial sector, service sector, irrigation and livestock production in period $\mathrm{t}$ $\left(¥ \mathrm{RMB} / \mathrm{m}^{3}\right.$ )

$C R F L_{t}, C R I N_{t}, C R S E_{t}$ The cost of water recycling technique for human living, industrial 
sector and service sector in period $\mathrm{t}\left(¥ \mathrm{RMB} / \mathrm{m}^{3}\right)$

$D H M_{t}, D H I_{t}, D H S_{t}, \quad$ Loss of flood per volume of surplus water being occured in period $\mathrm{t}$ $D H R_{t}, D H A_{t} \quad\left(¥ \mathrm{RMB} / \mathrm{m}^{3}\right)$

$F H M_{t h}, F H I_{t h}, F H S_{t h}, \quad$ Surplas water (flood water) for human living, industrial sector, $F H R_{t h}, F H A_{t h} \quad$ service sector, irrigation and livestock production in period $\mathrm{t}\left(\mathrm{m}^{3}\right)$

$\alpha \quad$ Credible measure

$V_{t h} \quad$ Water avaliability under probability $p_{t h}$ in period $\mathrm{t}\left(\mathrm{m}^{3}\right)$

$R_{t h} \quad$ Water inflow under probability $p_{t h}$ in period $\mathrm{t}\left(\mathrm{m}^{3}\right)$

$H_{t} \quad$ Normal water requirement of watercourse in period $\mathrm{t}\left(\mathrm{m}^{3}\right)$

$G_{t} \quad$ Evaporation and infiltration loss of water in period $\mathrm{t}\left(\mathrm{m}^{3}\right)$

$p_{t h} \quad$ Probability of random water availability $V_{t h}$ under level h (\%)

$S M_{t}^{\min }, S M_{t}^{\max } \quad$ Maximum population growth scale in floodplain in period $\mathrm{t}$ (person)

$S A_{t}^{\min }, S A_{t}^{\max } \quad$ Maximum irrigative area and wetland arear in floodplain in period $\mathrm{t}$ (tone)

$S I_{t}^{\min }, S I_{t}^{\max } \quad$ Maximum water demand for livestock breeding scale (tone) 


\section{List of Table Captions:}

2

3 Table 1. Economic data

4 Table 2. Scenario assumption

5 Table 3. Test the stability of the data

6 Table 4. Impact of population-industry transformation on water resources 
Table 1. Economic data

\begin{tabular}{|c|c|c|c|c|}
\hline \multicolumn{2}{|r|}{ Sector } & \multicolumn{3}{|c|}{ Period } \\
\hline & & $\mathrm{t}=1$ & $\mathrm{t}=2$ & $t=3$ \\
\hline \multicolumn{5}{|l|}{ Net benefit } \\
\hline \multirow[t]{2}{*}{ Human living } & Urban household $\left(¥ 10^{3} / 10^{3} \mathrm{~m}^{3}\right)$ & $(4.34,4.69,4.92)$ & $(4.45,4.78,4.98)$ & $(4.58,4.88,5.02)$ \\
\hline & Water for rural residents $\quad\left(¥ 10^{3} / 10^{3} \mathrm{~m}^{3}\right)$ & $(3.56,3.99,4.12)$ & $(3.62,4.02,4.18)$ & $(3.78,4.12,4.29)$ \\
\hline \multirow[t]{2}{*}{ Agriculture } & Irrigation $\left(¥ 10^{3} / 10^{3} \mathrm{~m}^{3}\right)$ & $(1.82,1.91,2.02)$ & $(1.96,2.06,2.13)$ & $(2.02,2.10,2.18)$ \\
\hline & Livestock $\left(¥ 10^{3} / 10^{3} \mathrm{~m}^{3}\right.$ ) & $(1.46,1.58,1.72)$ & $(1.53,1,67,1.82)$ & $(1.61,1.79,1.96)$ \\
\hline Industry & Industry $\left(¥ 10^{3} / 10^{3} \mathrm{~m}^{3}\right)$ & $(3.02,3.23,3.56)$ & $(3.08,3.28,3.62)$ & $(3.16,3.31,3.72)$ \\
\hline Service & Service $\quad\left(¥ 10^{3} / 10^{3} \mathrm{~m}^{3}\right)$ & $(2.12,2.34,2.76)$ & $(2.21,2.42,2.82)$ & $(2.34,2.58,2.92)$ \\
\hline Landscape & Artificial landscape $\left(¥ 10^{3} / 10^{3} \mathrm{~m}^{3}\right)$ & $(2.11,2.31,2.45)$ & $(2.18,2.36,2.52)$ & $(2.25,2.42,2.66)$ \\
\hline \multirow[t]{3}{*}{ Wetland } & Permanent river wetland $\quad\left(¥ 10^{3} / 10^{3} \mathrm{~m}^{3}\right)$ & $(1.31,1.38,1.42)$ & $(1.36,1.41,1.49)$ & $(1.39,1.47,1.53)$ \\
\hline & Seasonal river wetland $\left(¥ 10^{3} / 10^{3} \mathrm{~m}^{3}\right)$ & $(1.23,1.27,1.30)$ & $(1.26,1.29,1.35)$ & $(1.28,1.31,1.39)$ \\
\hline & Floodplain wetland $\left(¥ 10^{3} / 10^{3} \mathrm{~m}^{3}\right)$ & $(1.11,1.19,1.22)$ & $(1.14,1.21,1.24)$ & $(1.16,1.23,1.28)$ \\
\hline \multicolumn{5}{|c|}{ Loss of water shortage } \\
\hline \multirow[t]{2}{*}{ Human living } & Urban household water $\left(¥ 10^{3} / 10^{3} \mathrm{~m}^{3}\right)$ & $(5.23,5.68,5.92)$ & $(5.28,5.72,5.99)$ & $(5.36,5.79,6.06)$ \\
\hline & Water for rural residents $\quad\left(¥ 10^{3} / 10^{3} \mathrm{~m}^{3}\right)$ & $(4.23,4.78,4.96)$ & $(4.36,4.82,5.02)$ & $(4.48,4.98,5.12)$ \\
\hline \multirow[t]{2}{*}{ Agriculture } & Irrigation $\left(¥ 10^{3} / 10^{3} \mathrm{~m}^{3}\right)$ & $(2.42,2.53,2.67)$ & $(2.46,2.59,2.72)$ & $(2.52,2.63,2.86)$ \\
\hline & Livestock $\left(¥ 10^{3} / 10^{3} \mathrm{~m}^{3}\right.$ ) & $(1.68,1.86,1.98)$ & $(1.71,1.92,2.04)$ & $(1.78,1.98,2.12)$ \\
\hline Industry & Industry $\left(¥ 10^{3} / 10^{3} \mathrm{~m}^{3}\right)$ & $(3.68,3.89,3.99)$ & $(3.72,3.93,4.05)$ & $(3.81,3.99,4.12)$ \\
\hline Service & Service $\quad\left(¥ 10^{3} / 10^{3} \mathrm{~m}^{3}\right)$ & $(2.34,2.69,2.87)$ & $(2.41,2.73,2.96)$ & $(2.49,2.81,3.03)$ \\
\hline Landscape & Artificial landscape $\left(¥ 10^{3} / 10^{3} \mathrm{~m}^{3}\right)$ & $(2.45,2.72,2.88)$ & $(2.51,2.81,2.92)$ & $(2.68,2.91,3.02)$ \\
\hline \multirow[t]{3}{*}{ Wetland } & Permanent river wetland $\left(¥ 10^{3} / 10^{3} \mathrm{~m}^{3}\right)$ & $(1.58,1.62,1.73)$ & $(1.62,1.69,1.81)$ & $(1.72,1.89,1.99)$ \\
\hline & Seasonal river wetland $\left(¥ 10^{3} / 10^{3} \mathrm{~m}^{3}\right)$ & $(1.43,1.56,1.67)$ & $(1.49,1.63,1.72)$ & $(1.56,1.73,1.88)$ \\
\hline & Floodplain wetland $\left(¥ 10^{3} / 10^{3} \mathrm{~m}^{3}\right)$ & $(1.32,1.48,1.51)$ & $(1.41,1.52,1.63)$ & $(1.51,1.63,1.72)$ \\
\hline
\end{tabular}


Table 2. Scenario assumption

\begin{tabular}{|c|c|c|c|c|}
\hline \multirow[t]{3}{*}{ Abbreviation } & \multicolumn{4}{|c|}{ Scenario assumption } \\
\hline & \multicolumn{2}{|c|}{ Technique improvement } & \multirow{2}{*}{ Withdrawn farmland to wetland (ha) } & \multirow{2}{*}{ Water diversion from other source $\left(10^{6} \mathrm{~m}^{3}\right.$} \\
\hline & Water saving $(\%)$ & Water recycling $(\%)$ & & \\
\hline S0 (basic scenario) & 0 & 0 & 0 & 0 \\
\hline $\mathrm{S} 1$ & 5 & 0 & 0 & 0 \\
\hline S2 & 15 & 0 & 0 & 0 \\
\hline S3 & 5 & 5 & 0 & 0 \\
\hline S4 & 15 & 15 & 0 & 0 \\
\hline S5 & 0 & 0 & The area of wetlands being 2 times & 0 \\
\hline S6 & 0 & 0 & The area of wetlands being 4 times & 0 \\
\hline S7 & 0 & 0 & & Total water availability reaching 8 \\
\hline S8 & 0 & 0 & & Total water availability reaching 10 \\
\hline S9 & 5 & 5 & The area of wetlands being 2 times & 0 \\
\hline $\mathrm{S} 10$ & 15 & 15 & The area of wetlands being 4 times & 0 \\
\hline S11 & 5 & 5 & The area of wetlands being 2 times & Total water availability reaching 8 \\
\hline $\mathrm{S} 12$ & 15 & 15 & The area of wetlands being 4 times & Total water availability reaching 10 \\
\hline
\end{tabular}


Table 3. Test the stability of the data

2

\begin{tabular}{ccccccc}
\hline Variable & $\begin{array}{c}\text { Test type } \\
(\mathrm{C}, \mathrm{T}, \mathrm{P})\end{array}$ & $\begin{array}{c}\mathrm{ADF} \\
\text { statistic }\end{array}$ & $\begin{array}{c}1 \% \text { critical } \\
\text { value }\end{array}$ & $\begin{array}{c}5 \% \text { critical } \\
\text { value }\end{array}$ & $\begin{array}{c}10 \% \text { critical } \\
\text { value }\end{array}$ & $\begin{array}{c}\text { Conclus } \\
\text { ion }\end{array}$ \\
\hline $\begin{array}{c}\text { Transformation of } \\
\text { industry }\end{array}$ & $(1,1,0)$ & -3.666 & -4.380 & -3.600 & -3.240 & Steady \\
$\begin{array}{c}\text { Transformation of service } \\
\text { industry }\end{array}$ & $(1,1,1)$ & -4.163 & -4.380 & -3.600 & -3.240 & Steady \\
$\begin{array}{c}\text { Fluctuation of population } \\
\text { density }\end{array}$ & $(1,1,1)$ & -5.896 & -4.380 & -3.600 & -3.240 & Steady \\
$\quad$ GDP & $(1,1,2)$ & 3.375 & -4.380 & -3.600 & -3.240 & Steady \\
$\begin{array}{c}\text { Average GDP per person } \\
\text { Water demand }\end{array}$ & $(1,1,2)$ & -3.762 & -4.380 & -3.600 & -3.240 & Steady \\
& $(1,1,1)$ & -4.572 & -4.380 & -3.600 & -3.240 & Steady \\
\hline
\end{tabular}

3

4 
1 Table 4. Impact of population-industry transformation on water resources

2

\begin{tabular}{cccc}
\hline Y-dependent variable & ln GDP & ln average GDP per person & Ln water demand \\
X- independent variable & & & \\
\hline Transformation of & $\mathbf{0 . 0 1 9 * *}$ & $\mathbf{0 . 0 1 7 *}$ & $\mathbf{0 . 0 3 9}$ \\
industry & $(\mathbf{2 . 4 9 )}$ & $\mathbf{2 . 2 1}$ & $(\mathbf{1 . 6 1})$ \\
Transformation of service & $\mathbf{0 . 0 1 1}$ & $\mathbf{0 . 0 1 0}$ & $\mathbf{0 . 0 6 3} * *$ \\
industry & $\mathbf{( 0 . 7 0 )}$ & $\mathbf{( 0 . 6 8 )}$ & $(\mathbf{2 . 4 2})$ \\
Fluctuation of population & 0.003 & 0.001 & $-0.008^{*}$ \\
density & $(1.12)$ & $(0.27)$ & $(-1.77)$ \\
\hline
\end{tabular}




\section{List of Figure Captions:}

Figure 1. An adaptive water resource management framework with combined policies (AWFP) for mitigating adverse effects and risks on water resource in floodplain due to population-industry transformation

Figure 2. The location entropy of population-industry in Beijing-Tianjin-Hebei region from 2002 to 2019

Figure 3. Risks of water shortage, soil loss and flood control based on current population-industry scale in period 1 under $\mathrm{S} 0$ when $\alpha$ is 0.6

Figure 4. Total water shortages among various industrial sectors with consideration of technique improvement ( $\mathrm{S} 1$ to $\mathrm{S} 4$ ) when $\alpha$ is 0.6

Figure 5. Water shortages and corresponding shortage ratios between irrigation and wetland with consideration of withdrawn farmland to wetland (S5 to S6) when $\alpha$ are 0.6 and 0.99

Figure 6. Optimal water allocations with consideration of water diversion (S7 to S8) when $\alpha$ are 0.6 and 0.9

Figure 7. Water shortages and flood controls under S0 to S12 when $\alpha$ are 0.6 and 0.9 Figure 8. Coupla risks of water shortage, soil loss and flood control under S0 to S12 when $\alpha$ is 0.6

Figure 9. System benefits under S1 to S12 when $\alpha$ are 0.6 and 0.9 


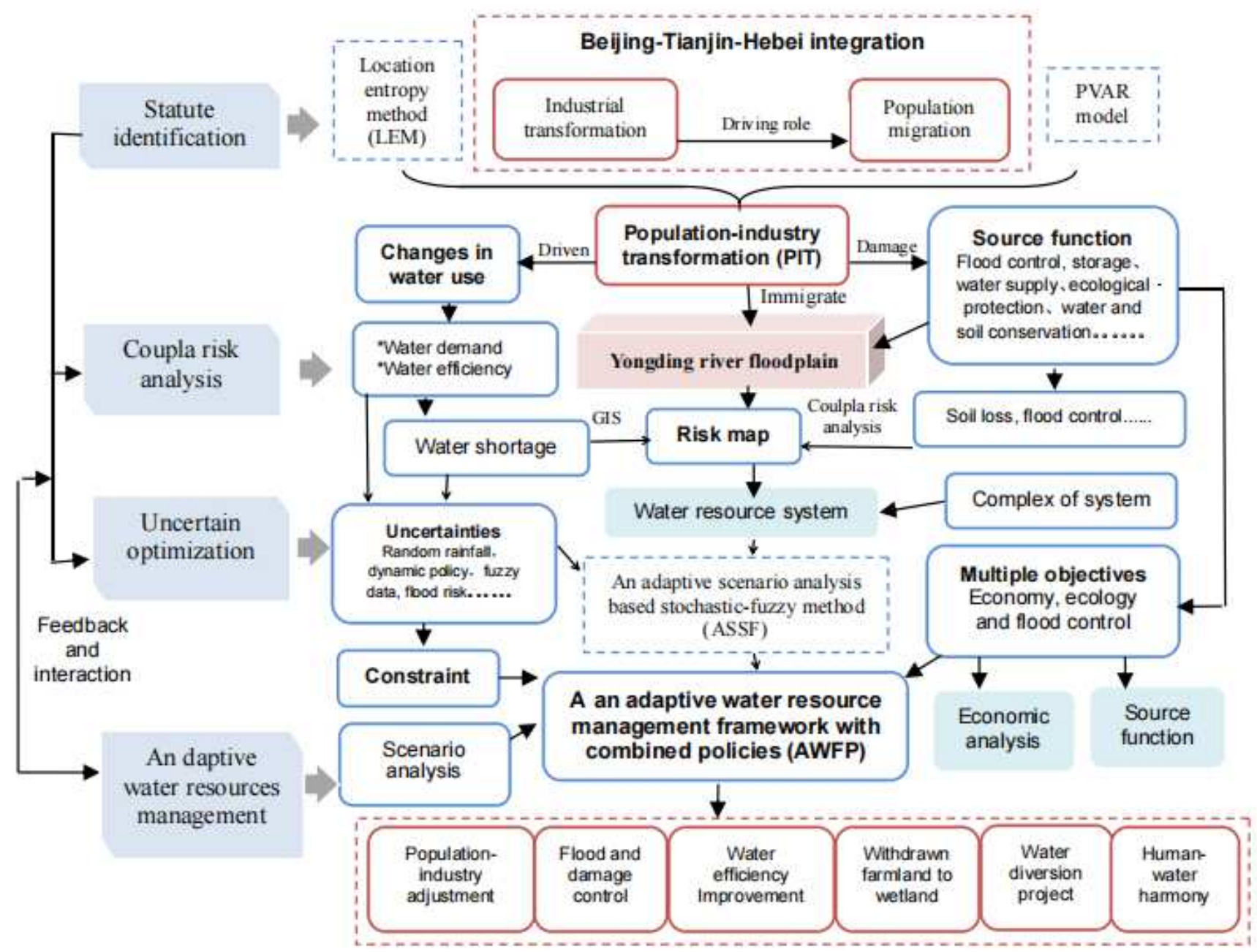

Figure 1. An adaptive water resource management framework with combined policies

(AWFP) for mitigating adverse effects and risks on water resource in floodplain due

to population-industry transformation 
(a1) 2008

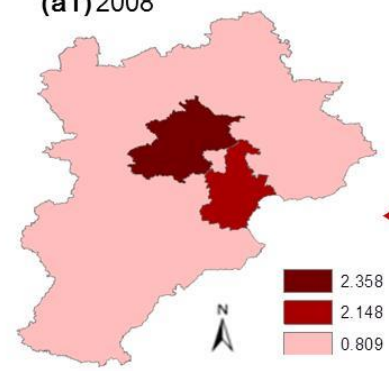

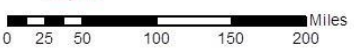
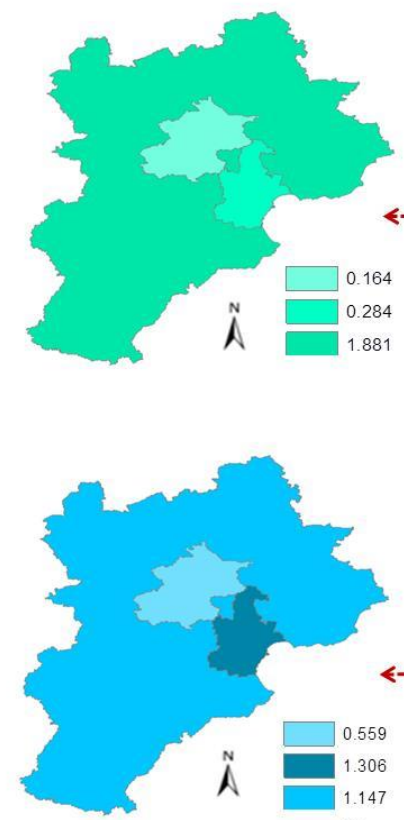

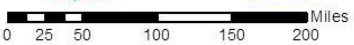

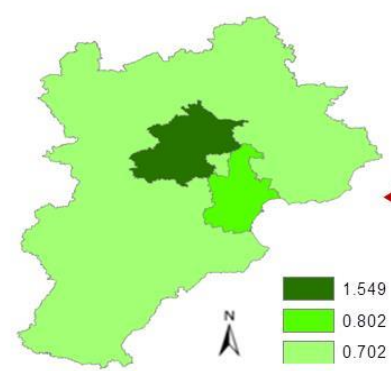

\begin{tabular}{llllll}
\hline & 25 & 50 & 100 & 150 & 200
\end{tabular} (a) Location entropy of population

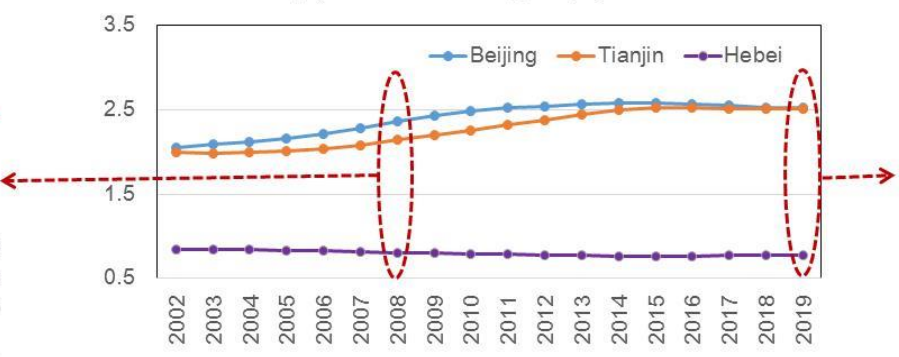

Year

(b) Location entropy of agricultrue

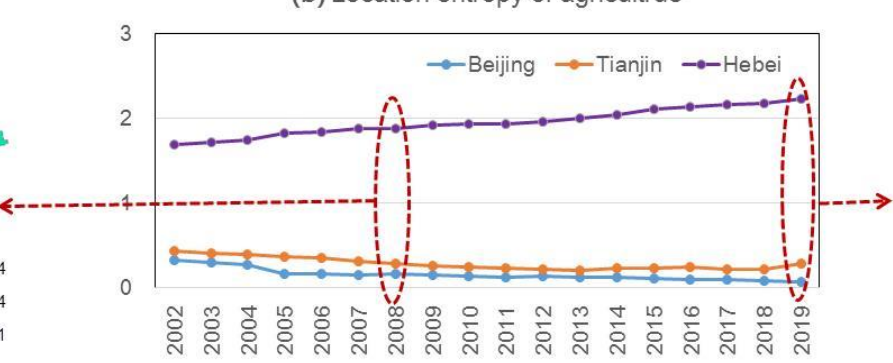

Year

(c) Location entropy of industry

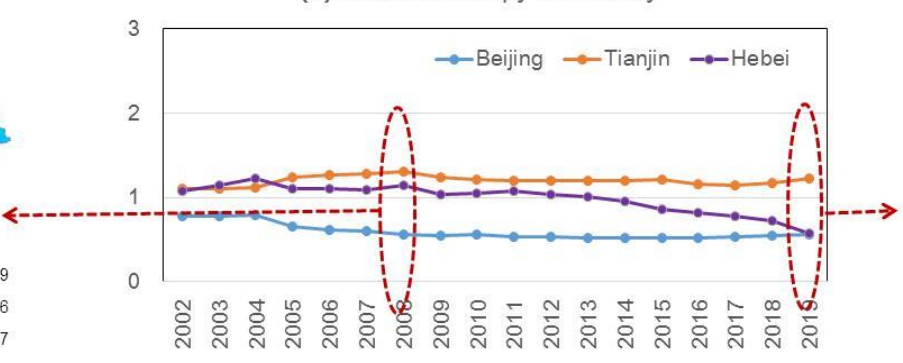

Year

(d) Location entropy of service

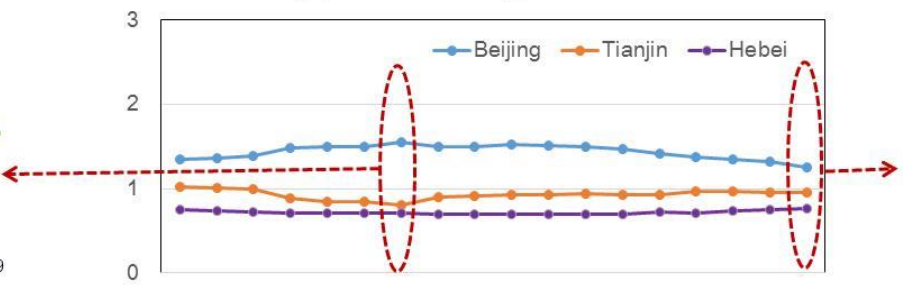

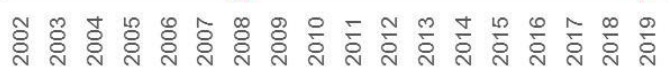

Year
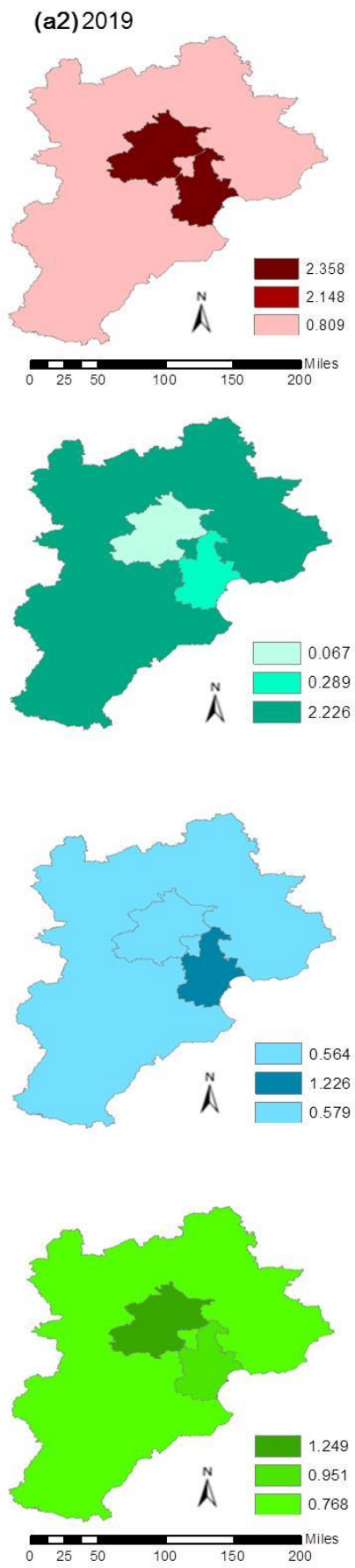

Figure 2. The location entropy of population-industry in Beijing-Tianjin-Hebei region from 2002 to 2019 


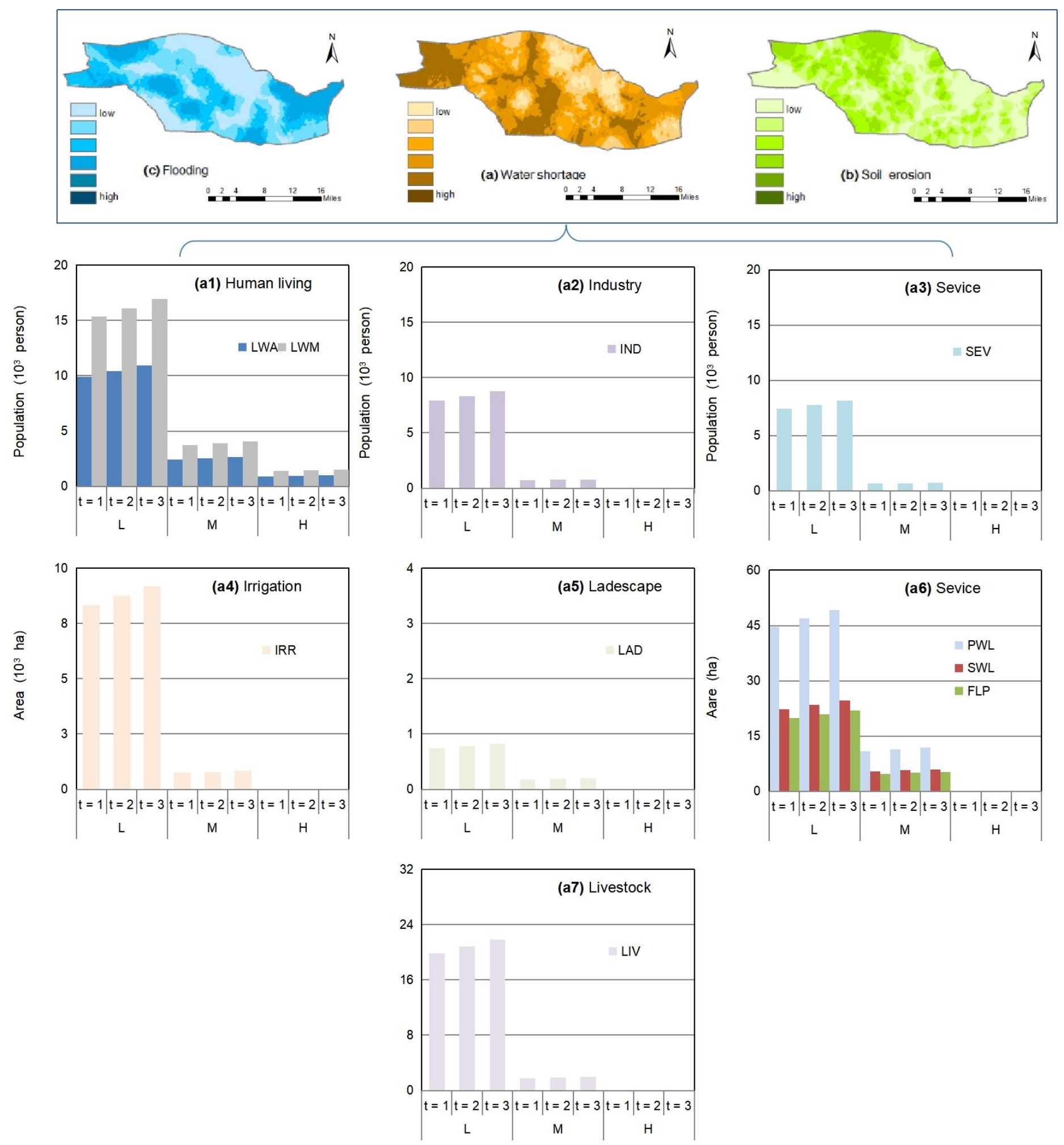

Figure 3. Risks of water shortage, soil loss and flood control based on current population-industry scale in period 1 under $\mathrm{S} 0$ when $\alpha$ is 0.6 

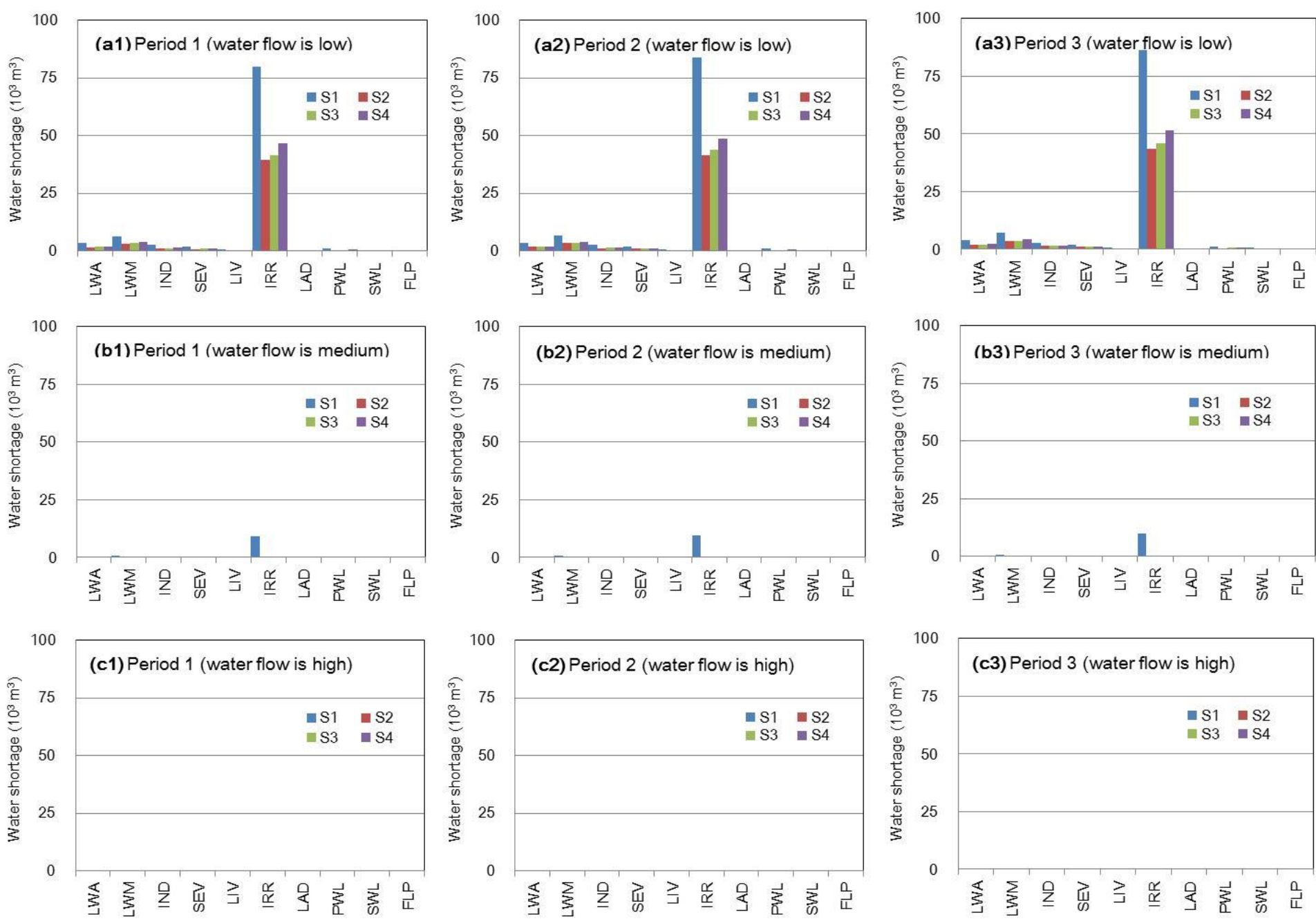

Figure 4. Total water shortages among various industrial sectors with consideration of technique improvement ( $\mathrm{S} 1$ to $\mathrm{S} 4)$ when $\alpha$ is 0.6 


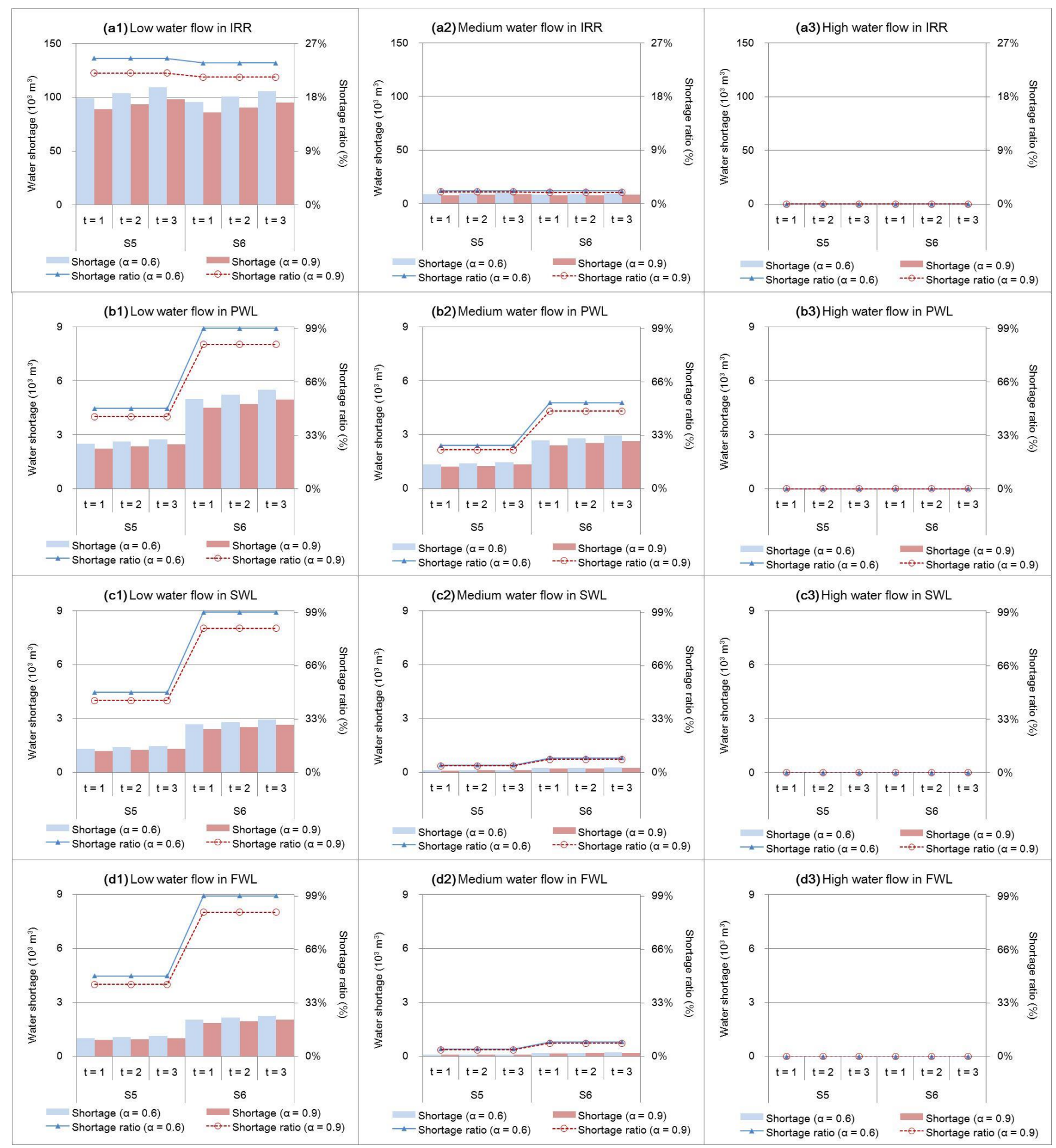

Figure 5. Water shortages and corresponding shortage ratios between irrigation and

wetland with consideration of withdrawn farmland to wetland (S5 to S6) when $\alpha$ are

0.6 and 0.99 

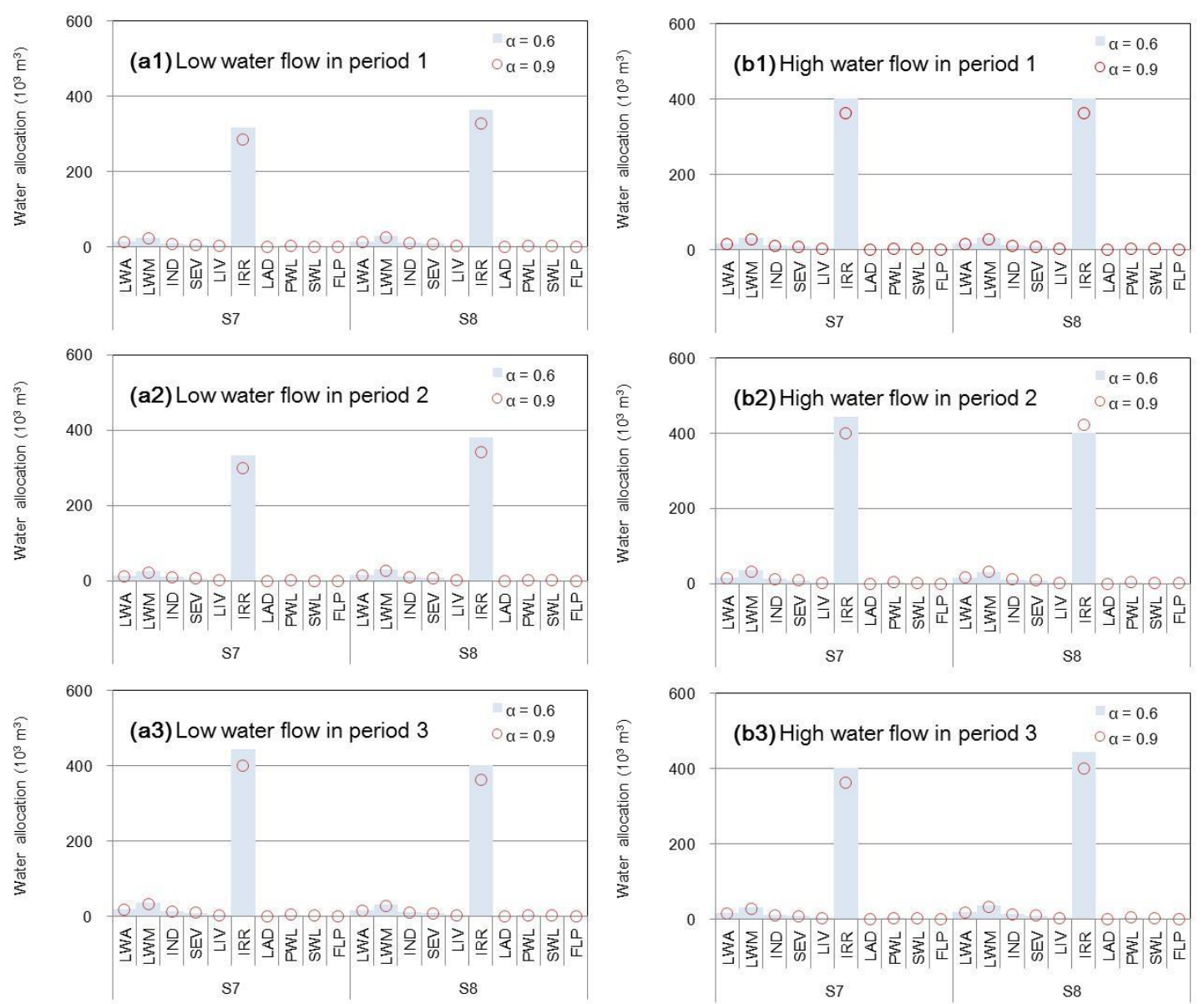

Figure 6. Optimal water allocations with consideration of water diversion (S7 to S8)

when $\alpha$ are 0.6 and 0.9 

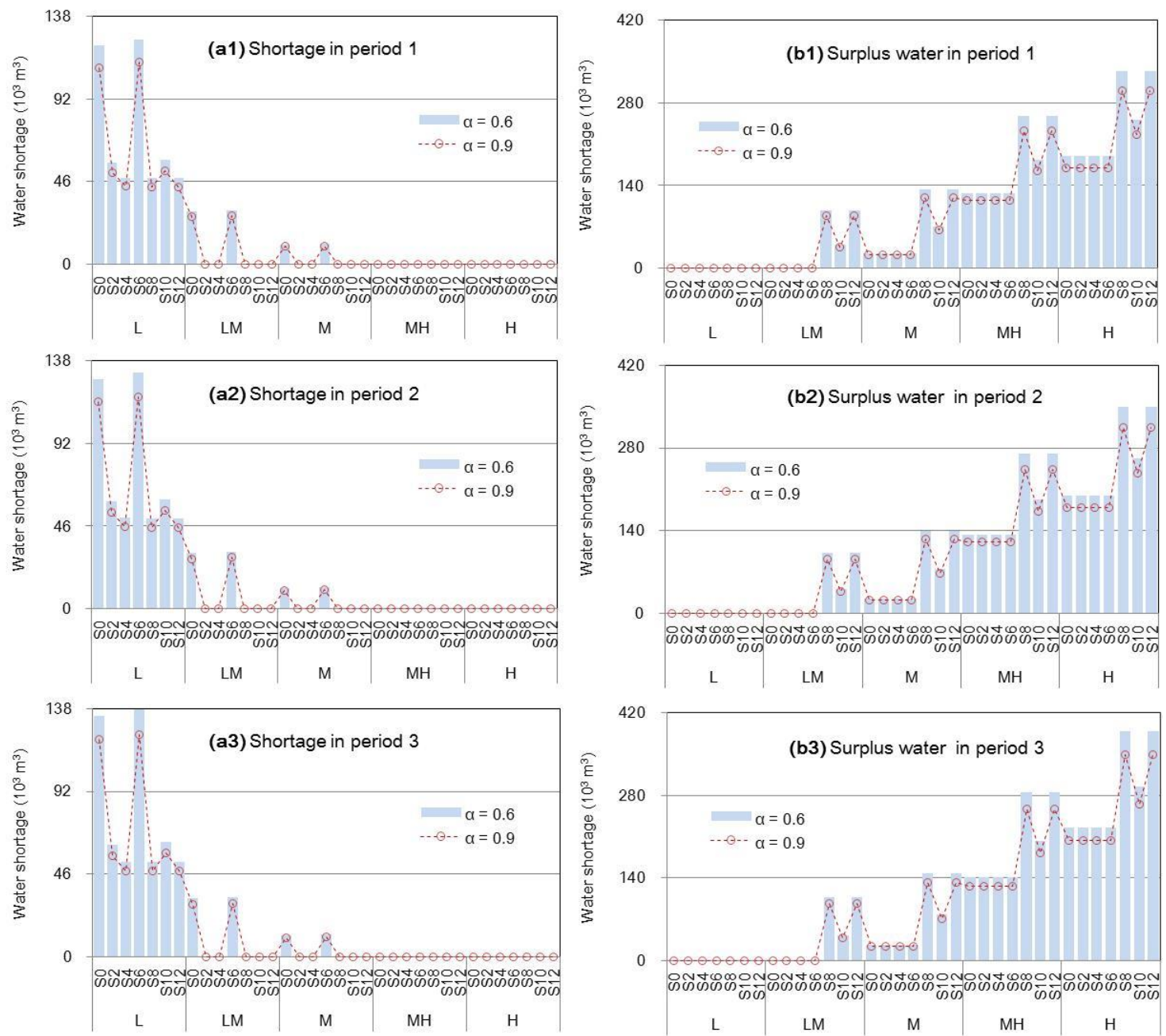

Figure 7. Water shortages and flood controls under $\mathrm{S} 0$ to $\mathrm{S} 12$ when $\alpha$ are 0.6 and 0.9 


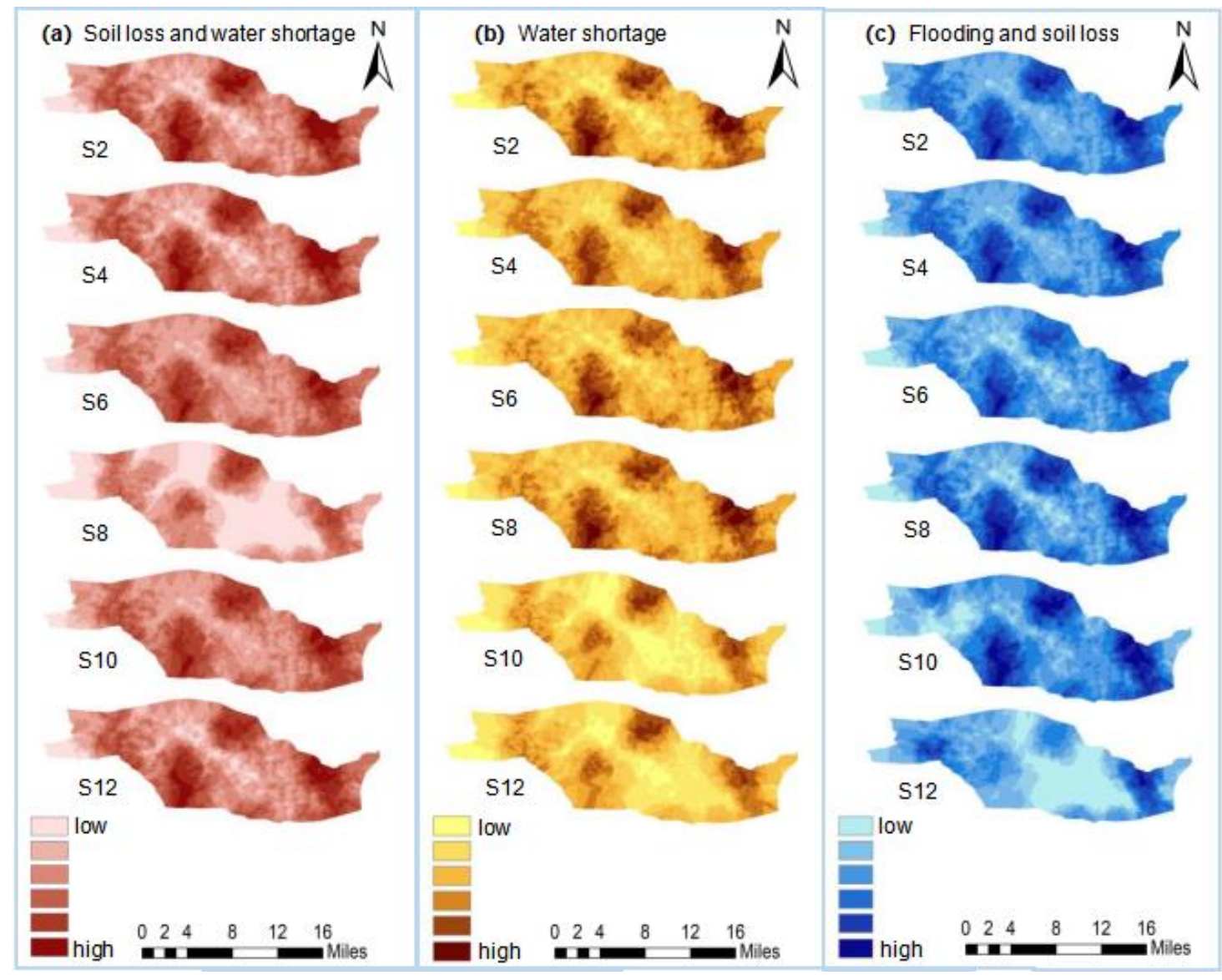

Figure 8. Coupla risks of water shortage, soil loss and flood control under S0 to S12 when $\alpha$ is 0.6 


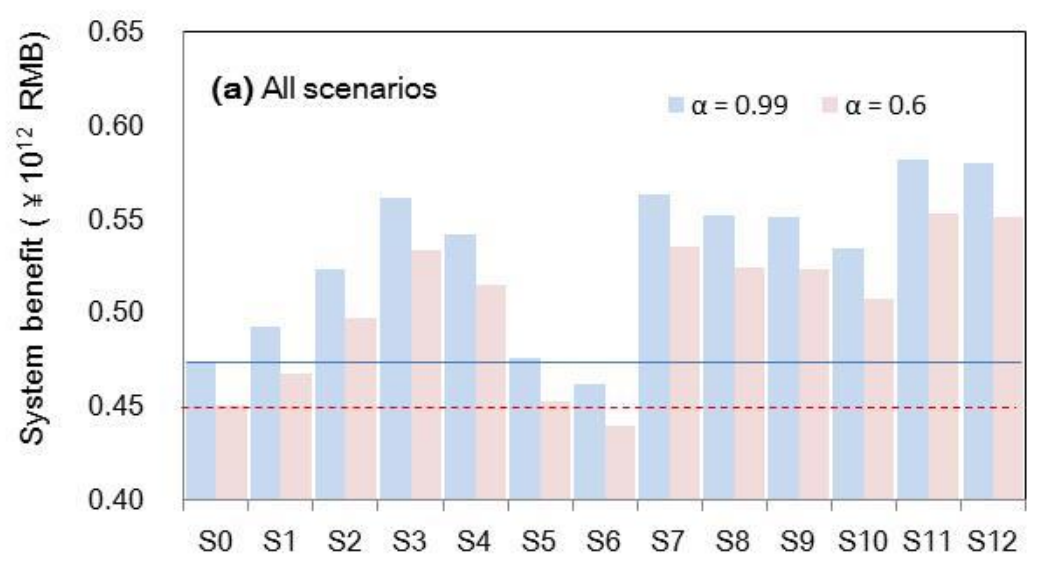

Figure 9. System benefits under S1 to S12 when $\alpha$ are 0.6 and 0.9 